\title{
Surfaces and Interfaces
}

\section{Effect of annealing treatment on microstructure and mechanical properties of cold sprayed TiB2/AISi10Mg composites \\ --Manuscript Draft--}

\begin{tabular}{|c|c|}
\hline Manuscript Number: & SURFIN-D-21-00543R2 \\
\hline Article Type: & Research Paper \\
\hline Keywords: & $\begin{array}{l}\text { additive manufacturing; cold spray; Metal Matrix Composite; Heat Treatment; } \\
\text { Mechanical properties }\end{array}$ \\
\hline Corresponding Author: & $\begin{array}{l}\text { Xinliang XIE } \\
\text { Louvain la Neuve, BELGIUM BELGIUM }\end{array}$ \\
\hline First Author: & Xinliang XIE \\
\hline \multirow[t]{12}{*}{ Order of Authors: } & Xinliang XIE \\
\hline & Chaoyue Chen \\
\hline & Zhe Chen \\
\hline & Ahmed Addad \\
\hline & Yingchun Xie \\
\hline & Hongjian Wu \\
\hline & Christophe Verdy \\
\hline & Yan Wang \\
\hline & Jiang Wang \\
\hline & Zhongming Ren \\
\hline & Gang Ji \\
\hline & Hanlin Liao \\
\hline Abstract: & $\begin{array}{l}\text { Cold spray allows for fabricating metal matrix composites or repairing damaged } \\
\text { components in a scalable way with a high deposition rate. Nevertheless, the poorly } \\
\text { bonded interfaces (both metallic splats/splats and metallic splats/reinforcements) and } \\
\text { pores in the composite deposit result in undesirable mechanical performance, which } \\
\text { limits its applications for load-bearing components. In this study, a special designed } \\
\text { composite powder reinforced with in-situ TiB } 2 \text { particles was used as the feedstock to } \\
\text { produce TiB } 2 \text { /AISi10Mg composite components by CS additive manufacturing. } \\
\text { Following this, the effect of post-annealing treatment on interfaces and micro-pores } \\
\text { healing, microstructure evolution, and mechanical properties of the cold sprayed } \\
\text { TiB2/AISi10Mg composites was investigated in terms of X-ray diffraction, electron } \\
\text { backscatter diffraction, transmission electron microscopy, and tensile test. The cold } \\
\text { sprayed composite exhibited a bimodal structure with ultrafine grains formed at the } \\
\text { inter-splat boundaries due to dynamic recrystallization induced by intensive plastic } \\
\text { deformation of the particles. In addition to the uniformly dispersed TiB } 2 \\
\text { nanoparticles, some aggregated clusters remained embedded in the Al matrix. Tensile } \\
\text { tests revealed that the as-sprayed deposits possessed very high tensile strength but } \\
\text { almost no toughness due to the poorly bonded inter-splats and enhanced work } \\
\text { hardening effect. Significant improvement in ductility was achieved in the annealed } \\
\text { samples through improvement of metallurgical bonding between the deformed splats, } \\
\text { release of residual stress, and static recrystallization. Interestingly, when the annealing } \\
\text { temperature was increased up to } 500{ }^{\circ} \mathrm{C} \text {, both the pure AlSi10Mg and TiB } 2 \\
\text { /AISi10Mg composite samples fractured at a very early stage due to the presence of } \\
\text { large pores (>20 } 4 \mathrm{~m} \text { ) which may originate from the moisture of initial powders. The in- } \\
\text { situ formed TiB } 2 \text { nanoparticles play an important role in strengthening the Al matrix, } \\
\text { meanwhile, maintaining a good ductility due to the robust interface bonding. This study } \\
\text { demonstrates the potential of using a gas-atomized composite powder to produce } \\
\text { high-performance metal matrix composites by cold spray additive manufacturing }\end{array}$ \\
\hline
\end{tabular}


followed by annealing treatment.

\section{Suggested Reviewers:}

Rocco Lupoi

The University of Dublin Trinity College

lupoir@tcd.ie

Prof.Lupoi worked on cold spraying for many years and published high

level articles in this field

Jean-François Silvain

Institut de Chimie de la Matière Condensée de Bordeaux: Institut de Chimie de la

Matiere Condensee de Bordeaux

Jean-francois.Silvain@icmcb.cnrs.fr

Prof.Jean - François Silvain has 30 years' experience on processing and

characterization of ceramic and inorganic multi materials going from metal and ceramic matrix composite to functionally graded materials, expeically for aluminium matrix composites.

Wenya Li

Northwestern Polytechnical University

liwy@nwpu.edu.cn

Prof.Li have rich research experience in cold spraying, especially for

the Al alloy and Al matrix composite coatings.

Response to Reviewers: 
Dear Editor,

We would like to submit the article entitled "Effect of annealing treatment on Microstructure and mechanical properties of cold sprayed TiB $2 / A l$ SilOMg composites" to your esteemed journal, "Surfaces and Interfaces".

As an emerging solid-state powder deposition technique, cold spray has been developed as a promising surface and additive manufacturing (AM) method to fabricate free-standing metal components and to repair damaged metallic components. The premature failure of components due to poor interface bonding of the deformed particles is the most critical issue in cold spray AM. As such, very limited applications of this emerging technique have been exploited to structural load-bearing parts so far, particularly for the metal matrix composites.

In this study, a novel AM strategy allowing for scalable manufacturing Al matrix composites was developed by cold spraying combining composite powder design, and interface strengthening via post annealing treatment. In-situ nano- $\mathrm{TiB}_{2}$ reinforced $\mathrm{AlSi} 10 \mathrm{Mg}$ composite powder was gas-atomized and used as feedstock for cold spraying. By using such a special designed composite powder, it was expected to solve the problems of the nonuniform distribution of reinforced particles, poor interface bonding between the ceramic particles and metal matrix, and low deposition efficiency. To this end, we achieved significant improvement in ductility and strength of the cold sprayed Al matrix composite, which represents a breakthrough. The strengthening and toughing mechanisms were discussed in light of detailed experimental evidences obtained by SEM/EBSD and TEM characterization. This demonstrates the potential of the gas-atomized composite powder for producing high-performance metal matrix composites by solid-state cold spray AM combining annealing treatment.

Finally, this paper is our original unpublished work. All authors have seen the manuscript and approved to submit to your journal.

We hope the paper will be published rapidly under your supervision. With our best wishes.

Sincerely yours

Prof. Gang JI

Unité Matériaux et Transformations, CNRS UMR 8207

Université de Lille

Villeneuve d'Ascq 59655, France

Email : gang.ji@univ-lille1.fr 
Dear editor,

We sincerely thank the reviewers for their kind suggestions. In the following you can find our detailed replies to the question of the reviewer. All the relevant corrections are highlighted in red color in the revised manuscript.

Reviewer \#3: This article focuses on improving the mechanical properties of cold sprayed Al matrix composites by introducing a special designed composite powder and annealing treatment. The results are interesting. Prior to publish, the authors are asked to reconsider the following statements and points.

1. In the introduction section, "these techniques still show limitations in damage repair and netshape components forming" powder metallurgy could be a net-shape/near net-shape manufacturing technology, please check this.

Response: This statement has been modified in the revised version.

2. In the introduction section, "the post-heat treatments showed very limited improvement in the tensile properties of these CS composites mainly due to the insufficient healing of the poorly bonded interfaces". Here, the authors should notice that the interfaces mean those between $\mathrm{Al}$ matrix and reinforced ceramic particles. The interfaces between the $\mathrm{Al}$ particles surely are improved as reported in (Materials \& Design, 2011, 32(1), 388-394).

Response: As advised, this statement has been modified in the revised version. " the post-heat treatments showed very limited improvement in tensile properties of these CS composites mainly due to the insufficient healing of the poorly bonded interfaces between the $\mathrm{Al}$ matrix and ceramic reinforced particles".

3. The authors are asked to add more examples showing the importance of annealing treatment on improving mechanical property of cold sprayed components.

Response: As suggested, more examples on annealing treatment of the cold sprayed components have been added in the revised version.

"Significant improvement in both the tensile strength and elongation of the CS 316L stainless steel was achieved by vacuum annealing treatment due to the absence of the oxide inclusions and a considerably enhanced bonding strength at the inter-particle interfaces [29]. Moreover, heat treatment (solution and aging treatment) was applied to improve the mechanical properties of CS Al alloys, such as 6061 Al [31] and 7075 Al [32, 33].”

4. Could you point out the chemical reactions between these two salts to produce such a in-situ reinforced composite powder?

Response: The chemical reaction between the salts of $\mathrm{K}_{2} \mathrm{TiF}_{6}$ and $\mathrm{KBF}_{4}$ is $3 \mathrm{~K}_{2} \mathrm{TiF}_{6}+6 \mathrm{KBF}_{4}+$ $10 \mathrm{Al} \rightarrow 9 \mathrm{KAlF}_{4}+\mathrm{K}_{3} \mathrm{AlF}_{6}+3 \mathrm{TiB}_{2}$ in melted pure $\mathrm{Al}$ at around $900{ }^{\circ} \mathrm{C}$.

5. In addition, tensile tests on $200^{\circ} \mathrm{C}$ were missing, including EBSD analysis, please add some description about its absence. 
Response: Actually, the samples treated at $200^{\circ} \mathrm{C}$ for $4 \mathrm{~h}$ showed hardly microstructure changes and very limited improvement in tensile properties compared to the as-sprayed sample.

6. The authors are encouraged to have a more comprehensive discussion about the effect of annealing treatment on microstructure and properties.

Response: More discussions on the effect of annealing treatment on microstructure and properties were added in the discussion section.

"According to Li et al. [65], annealing treatment can affect the interface bonding of the deformed Al particles, recrystallization, grain growth and work hardening effect generated during CS deposition, while little effect on the sizes, morphologies and distribution of the reinforced particles (TiN) was found in the CS TiN/5056Al composite. The dispersion of reinforced particles plays a greater role in strengthening the CS Al composite than the strain hardening effect of TiN tamping on the Al matrix after annealing treatment [66]. In this study, annealing treatment was applied to improve the mechanical performance of the CS $\mathrm{TiB}_{2} / \mathrm{AlSi} 10 \mathrm{Mg}$ components by reducing defects (e.g. micro-pores) and strengthening the intersplat bonding through atom diffusion." 


\section{Effect of annealing treatment on microstructure and mechanical}

\section{properties of cold sprayed $\mathrm{TiB}_{2} / \mathrm{AISi10Mg}$ composites}

Xinliang Xie ${ }^{1,2,5^{*}}$, Chaoyue Chen ${ }^{3}$, Zhe Chen ${ }^{4}$, Ahmed $\mathrm{Addad}^{2}$, Yingchun Xie ${ }^{6}$, Hongjian $\mathrm{Wu}^{1}$, Christophe Verdy ${ }^{1}$, Yan, Wang ${ }^{7}$, Jiang, Wang ${ }^{3}$, Zhongming Ren ${ }^{3}$, Gang $\mathrm{Ji}^{2 *}$, Hanlin

Liao $^{1}$

1. ICB UMR 6303, CNRS, Univ. Bourgogne Franche-Comté, UTBM, F-90010 Belfort, France

2. Univ. Lille, CNRS, INRA, ENSCL, UMR 8207 - UMET - Unité Matériaux et Transformations, F-59000 Lille, France

3. Shanghai University \& State Key Laboratory of Advanced Special Steel, 149 Yanchang Road, Shanghai 200072, P.R. China

4. State Key Laboratory of Metal Matrix Composites, Shanghai Jiao Tong University, Shanghai 200240, China

5. Institute of Mechanics, Materials and Civil Engineering, UCLouvain, Louvain-la-Neuve, Belgium

6. The Key Lab of Guangdong for Modern Surface Engineering Technology, National Engineering Laboratory for Modern Materials Surface Engineering Technology, Institute of New Materials, Guangdong Academy of Sciences, Guanzhou, 510651, China

7. School of Metallurgical Engineering, Xi'an University of Architecture and Technology, Xi'an 710055, China

Abstract: Cold spray allows for fabricating metal matrix composites or repairing damaged components in a scalable way with a high deposition rate. Nevertheless, the poorly bonded interfaces (both metallic splats/splats and metallic splats/reinforcements) and pores in the composite deposit result in undesirable mechanical performance, which limits its applications for load-bearing components. In this study, a special designed composite powder reinforced with in-situ $\mathrm{TiB}_{2}$ particles was used as the feedstock to produce $\mathrm{TiB}_{2} / \mathrm{AlSi} 10 \mathrm{Mg}$ composite components by CS additive manufacturing. Following this, the effect of post-annealing treatment on interfaces and micro-pores healing, microstructure evolution, and mechanical properties of the cold sprayed $\mathrm{TiB}_{2} / \mathrm{AlSi10Mg}$ composites was investigated in terms of $\mathrm{X}$-ray diffraction, electron backscatter diffraction, transmission electron microscopy, and tensile test. The cold sprayed composite exhibited a bimodal structure with ultrafine grains formed at the inter-splat boundaries due to dynamic recrystallization induced by intensive plastic deformation of the particles. In addition to the uniformly dispersed $\mathrm{TiB}_{2}$ nanoparticles, some aggregated 
clusters remained embedded in the Al matrix. Tensile tests revealed that the as-sprayed deposits possessed very high tensile strength but almost no toughness due to the poorly bonded intersplats and enhanced work hardening effect. Significant improvement in ductility was achieved in the annealed samples through improvement of metallurgical bonding between the deformed splats, release of residual stress, and static recrystallization. Interestingly, when the annealing temperature was increased up to $500{ }^{\circ} \mathrm{C}$, both the pure $\mathrm{AlSi} 10 \mathrm{Mg}$ and $\mathrm{TiB}_{2} / \mathrm{AlSi} 10 \mathrm{Mg}$ composite samples fractured at a very early stage due to the presence of large pores $(>20 \mu \mathrm{m})$ which may originate from the moisture of initial powders. The in-situ formed $\mathrm{TiB}_{2}$ nanoparticles play an important role in strengthening the $\mathrm{Al}$ matrix, meanwhile, maintaining a good ductility due to the robust interface bonding. This study demonstrates the potential of using a gas-atomized composite powder to produce high-performance metal matrix composites by cold spray additive manufacturing followed by annealing treatment.

Keywords: Additive manufacturing; Cold spray; Metal matrix composite; Heat treatment; Mechanical properties

\section{Introduction}

Particle-reinforced $\mathrm{Al}$ matrix composites (P-AMCs) were promising structural materials, which have been largely used in the aerospace and automotive industries thanks to their light weight, low coefficient of thermal expansion, high specific strength and stiffness, and good wear resistance [1-4]. P-AMCs, produced by conventional approaches like stir casting [5, 6], powder metallurgy [7] and thermal spray [8], are often accompanied with problems of high porosity, large grain size, clustering of particles, poor interface bonding and undesirable interfacial reactions, which can degrade their final mechanical performance. Moreover, these techniques still show some limitations in damage repair and net-shape components forming at the same time.

Nowadays, cold spray (CS) was proposed as a promising solid-state additive manufacturing (AM) technology to produce high-quality metallic components and to repair damaged components [9-11]. Unlike the laser or electron beam-based AM techniques and other hightemperature deposition processes, the formation of the CS deposits relies greatly on the particles' kinetic energy at impact rather than on its thermal energy or melting. During CS, powder particles are accelerated to supersonic velocity $(300-1200 \mathrm{~m} / \mathrm{s})$ via expansion of a pressurized gas through a diverging-converging nozzle. In general, successful bonding is achieved by severe plastic deformation of the particles and the formation of adiabatic shear instabilities (ASI) and/or interlocking [12-14]. Since the feedstock used remains in a solid-state during the entire deposition process, the initial property of the powder can be well maintained and the inevitable defects commonly encountered in the high-temperature deposition processes 
such as oxidation, residual thermal stress, or phase transformation can be minimized or eliminated [15-17]. Importantly, CS shows great potential to be used as AM or repairing technique owing to its high deposition rates (as high as $10 \mathrm{Kg} / \mathrm{h}$ ), low cost, and its feasibility to produce thick deposits or net-shape parts [9, 11, 18-21]. In recent years, a variety of engineering products have been fabricated by CSAM [11, 22-27]. For example, the CS process was employed to fabricate pure $\mathrm{Al}, \mathrm{Cu}, \mathrm{Ti}$, and 316SS thick deposits by Huang et al. [28]. Their results demonstrated that the as-sprayed deposits of these four types of materials had very low elongation due to the poor inter-splats bonding, which is a critical issue for the applications of CS components. Heat treatments are commonly used to further improve mechanical performance of the CS parts by enhancing the metallurgical bonding between splats and defects healing $[28,29]$. For instance, the Inconel 718 alloy fabricated using CS followed by heat treatment showed tensile properties comparable to those of the bulk counterpart [30]. Significant improvement in both the tensile strength and elongation of the CS 316L stainless steel was achieved by vacuum annealing treatment due to the absence of the oxide inclusions and a considerably enhanced bonding strength at the inter-particle interfaces [29]. Moreover, heat treatment (solution and aging treatment) was applied to improve the mechanical properties of $\mathrm{CS} \mathrm{Al}$ alloys, such as 6061 Al [31] and 7075Al [32, 33].

Until recently, various P-AMCs have been tentatively deposited by CS, such as Al12Si/SiC [34], $\mathrm{Al} / \mathrm{Al}_{2} \mathrm{O}_{3}$ [35-40], $\mathrm{Al} / \mathrm{TiN}$ [41], $\mathrm{Al} 5056 / \mathrm{SiC}$ [42, 43], $\mathrm{Al} / \mathrm{TiB}_{2}$ [44], 7075Al/SiC [45], 7075 $\mathrm{Al} / \mathrm{TiB}_{2}$ [45], Al/diamond [46]. However, previous studies mainly focused on fabricating AMC coatings and on the coating-related properties, such as microhardness, wear, and corrosion properties. Few attempts have been made to fabricate thick P-AMC deposits or components from the perspective of CSAM. This is because there are still considerable challenges in achieving robust bulk mechanical performance AMCs using CS. First, the poor interface bonding between the deformed splats as well as the ex-situ added reinforced particles and Al matrix can significantly degrade their final mechanical properties, particularly for the composite produced using mechanical blended mixtures [47]. Second, the CS AMCs generally have problems associated with large ceramic particle size $(>5 \mu \mathrm{m})$ and uneven distribution of the reinforcement phases, which also have an adverse effect on the final mechanical properties. As a result, the CS AMCs exhibited very low strength and almost no ductility (i.e. displaying completely brittle features) even though a fully dense composite structure was acquired [48] [49]. Moreover, the post-heat treatments showed very limited improvement in tensile properties of these CS composites mainly due to the insufficient healing of the poorly bonded interfaces between the Al matrix and ceramic reinforced particles [49]. In our previous study [50], to solve the above-mentioned issues, like uneven distribution of reinforcements and poor interfacial bonding between the reinforcement and the Al matrix, involved in the traditional CS process, a 
gas-atomized $\mathrm{TiB}_{2} / 7075 \mathrm{Al}$ composite powder was proposed to produce high-quality AMCs by CS. Once again, the as-sprayed composites samples exhibited high strength but very low ductility due to the limited metallurgical bonding between the deformed splats even through the optimized CS processing parameters were used. Therefore, it is of great necessity to develop novel CS approaches, which are capable to produce high-quality P-AMCs with designed mechanical performance.

This study aims to develop a scalable CSAM approach combing composite powder design and post-heat treatment to achieve high-performance P-AMCs. A gas-atomized AlSiOMg composite powder reinforced with in-situ nanosized $\mathrm{TiB}_{2}$ particles was used as the feedstock to produce AMC components by CSAM using helium as propellant gas. Fully dense and thick $\mathrm{TiB}_{2} / \mathrm{AlSi10Mg}$ components were revealed by CSAM. Following this, the influence of postheat treatments on microstructure evolution and mechanical performance were investigated in terms of X-ray diffraction (XRD), scanning (SEM) and Transmission electron microscopy (TEM) and electron backscatter diffraction (EBSD), microhardness, and tensile test. The fracture mechanisms corresponding to microstructure observation were discussed.

\section{Experimental details}

\subsection{Preparation of $\mathrm{TiB}_{2} / \mathrm{AlSi10Mg}$ composite powder}

The $\mathrm{TiB}_{2}$ reinforced $\mathrm{AlSi} 10 \mathrm{Mg}$ composite powder used in this work was produced by insitu chemical reaction of the mixed salts in the molten $\mathrm{Al}$ alloy followed by gas-atomization. First, $\mathrm{TiB}_{2}$ reinforcements were introduced into $\mathrm{Al}$ melt via the in-situ chemical reaction between the salts of $\mathrm{K}_{2} \mathrm{TiF}_{6}$ and $\mathrm{KBF}_{4}\left(3 \mathrm{~K}_{2} \mathrm{TiF}_{6}+6 \mathrm{KBF}_{4}+10 \mathrm{Al} \rightarrow 9 \mathrm{KAlF}_{4}+\mathrm{K}_{3} \mathrm{AlF}_{6}+3 \mathrm{TiB}_{2}\right)$ in furnace. Then, $\mathrm{Mg}$ (99.99\%, CHALCO) and Al-Si master (99.99\%, CHALCO) alloys were subsequently added into the melt and held for $10 \mathrm{~min}$ for homogenization. Afterward, the composite powder was atomized by pressurized Ar using a home-made gas-atomizer setup. The chemical composition of the powder was determined by inductively coupled plasma atomic emission analysis (ICP-AES), showing 9.8 wt.\% Si, 0.3 wt.\% Mg, 7.0 wt.\% TiB 2 ( 3.6 vol.\%) and $\mathrm{Al}$ balance. More details about the composite powder preparation can be found elsewhere $[50,51]$. The gas-atomized pure AlSi10Mg powder was also used as the feedstock for comparison.

\subsection{Cold spray process}

The powder feedstocks were deposited onto grit-blasted $\mathrm{Al}$ alloy plates with a dimension of $140 \times 80 \times 4 \mathrm{~mm}$ using a homemade CS system (LERMPS, UTBM, France), which is equipped with a de-Laval type polymer nozzle with an expansion ratio of 14.0. The CS deposition was 
performed in a helium recycle system, where the processing cost can be largely reduced. The inlet He gas kept at a temperature of around $320{ }^{\circ} \mathrm{C}$ and a pressure of around $1.8 \mathrm{MPa}$ during operating. The nozzle trajectory was repeated more than 25 times to obtain thick deposits $(>2.5$ $\mathrm{mm})$. Photographic overviews of the spayed deposits are shown in Fig. 1.

\subsection{Heat treatment of cold sprayed specimens}

To investigate the effect of post-heat treatment on microstructure and mechanical performance, the as-sprayed $\mathrm{AlSi} 10 \mathrm{Mg}$ and $\mathrm{TiB}_{2} / \mathrm{AlSi} 10 \mathrm{Mg}$ composite deposits were systematically heat-treated at temperatures ranging from $200{ }^{\circ} \mathrm{C}$ to $500{ }^{\circ} \mathrm{C}$ under high purity $\mathrm{Ar}$ environment for $4 \mathrm{~h}$.

\subsection{Microstructure and mechanical properties characterization}

X-ray diffractometer (Siemens D5000, Germany) was employed to identify the phase evolution after CS deposition and post-heat treatment. The microstructural observation of the samples was conducted using SEM (JSM5800LV, JEOL, Japan) equipped with an energydispersive spectroscopy unit [52]. Porosities of samples were measured by analyzing optical microscopy images using ImageJ software (NIH, Bethesda, Maryland, USA). Si particle size and quantity in the as-sprayed and annealed samples were determined by analyzing SEM images. EBSD characterization on the cross-section of the specimens was carried out using the FEI-Sirion SEM equipped with a TSL-OIM EBSD camera. TEM characterization was performed using an FEI Tecnai G2 microscope operated at $200 \mathrm{kV}$.

Microhardness was measured by a Vickers hardness indenter (Leitz, Germany) with a load of $100 \mathrm{~g}$ for $10 \mathrm{~s} .10$ positions were randomly tested to have an average value for each sample. specimens treated at $300{ }^{\circ} \mathrm{C}, 400{ }^{\circ} \mathrm{C}$, and $500{ }^{\circ} \mathrm{C}$ for $4 \mathrm{~h}$ were selected to investigate the tensile property of the CS deposits. Tensile tests were conducted on a Zwick/Roell Z100 machine at a strain rate of $1 \mathrm{~mm} / \mathrm{min}$. Before the tensile tests, the deposits were removed away from the substrates and cut in the direction being parallel with the nozzle moving direction. The tensile specimen has a total length of $70 \mathrm{~mm}$, a width of $2 \mathrm{~mm}$ in the gauge section, and a thickness of $2 \mathrm{~mm}$. At least 3 samples were tested at each condition. The fracture morphologies after tensile tests were observed using SEM. 


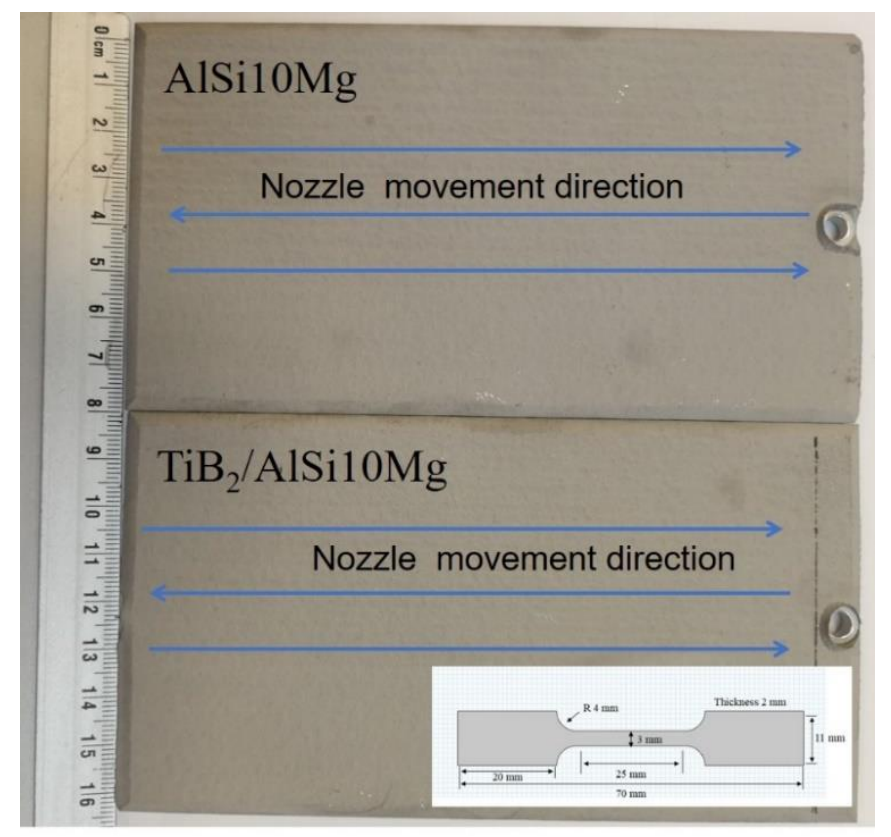

Fig. 1 Photographic overviews of the as-spayed deposits. The inserted schematic image shows the dimension size of the tensile specimen.

\section{Results and discussions}

\subsection{Powder characterization}

Fig. 2 shows the particle morphologies of the gas-atomized pure AlSi10Mg and $\mathrm{TiB}_{2} / \mathrm{AlSi} 10 \mathrm{Mg}$ composite powders observed by SEM. Both powders exhibit a near-spherical shape. Based on the measurements of laser diffraction sizer (Mastersizer 2000, Malvern Instruments Ltd., UK), the pure AlSi10Mg powder and $\mathrm{TiB}_{2} / \mathrm{AlSi} 10 \mathrm{Mg}$ composite powder possess similar size range with the average particle sizes of $45 \mu \mathrm{m}$ and $42 \mu \mathrm{m}$, respectively (see Fig. 2e). According to the EDS mapping (Fig. 3), eutectic Si forms interconnected networkstructure. In addition to the nanosized $\mathrm{TiB}_{2}$ particles, some clusters on the micrometer scale (as marked by red circles) are dispersed inside the composite particle. The inhomogeneous distribution of the $\mathrm{TiB}_{2}$ particles derives from the in-situ reaction and solidification process during gas-atomization. 

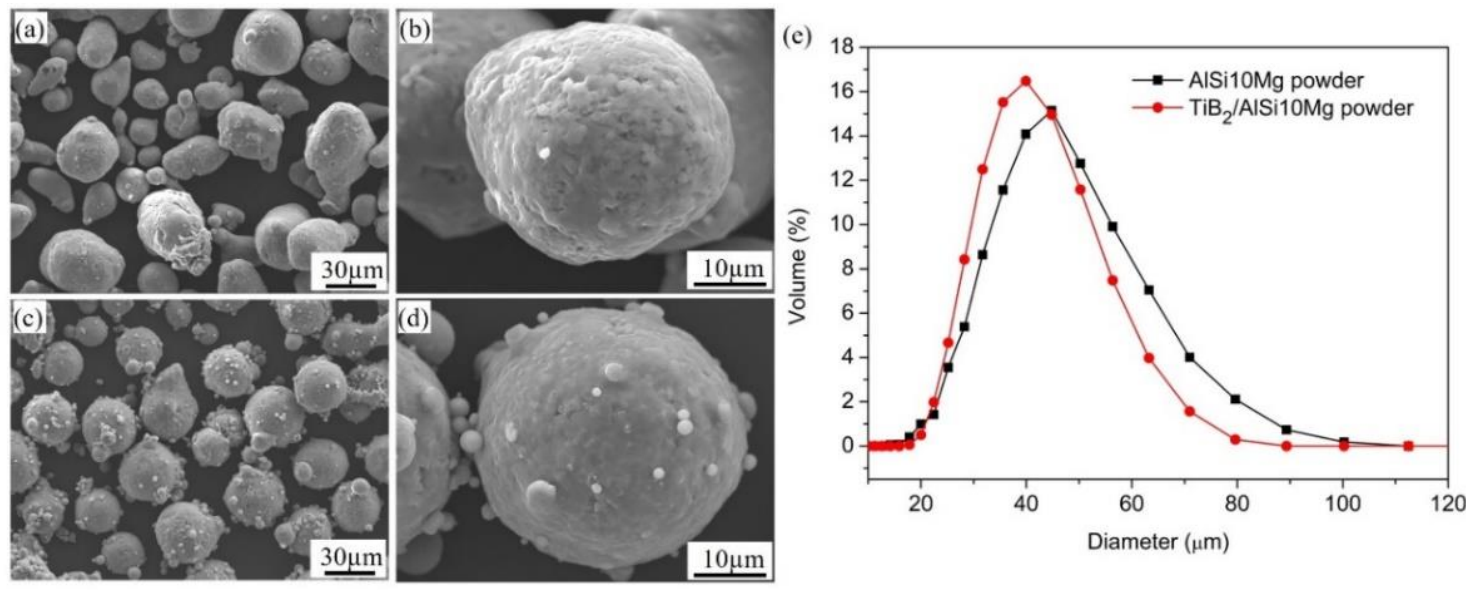

Fig. 2 Morphologies of the gas atomized powder feedstocks in different magnifications: (a) and (b) AlSi10Mg powder; (c) and (d) $\mathrm{TiB}_{2} / \mathrm{AlSi} 10 \mathrm{Mg}$ composite powder. (e) Particle size distributions.
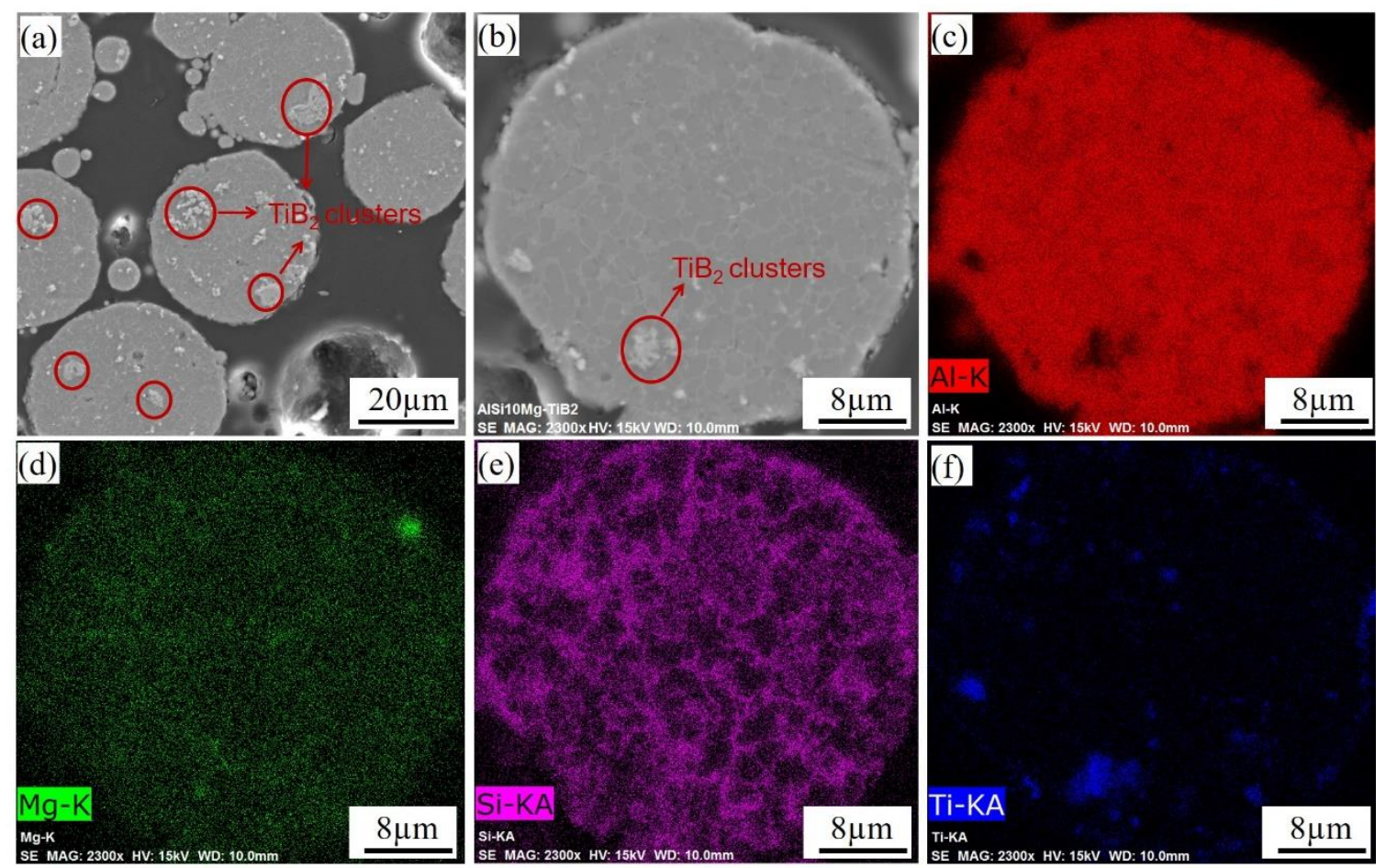

Fig. 3 Cross-sectional morphologies of the $\mathrm{TiB}_{2} / \mathrm{AlSi} 10 \mathrm{Mg}$ composite powder at (a) low and

(b) high magnifications; (c-f) corresponding EDS mapping. The element Ti represents the distribution of $\mathrm{TiB}_{2}$ particles.

\subsection{Phase composition}

The XRD patterns of the pure AlSi10Mg and $\mathrm{TiB}_{2} / \mathrm{AlSi} 10 \mathrm{Mg}$ composite in the as-sprayed and annealed states, as well as their initial powders, are shown in Fig. 4. The pure AlSi10Mg samples show the Al, Si, and $\mathrm{Mg}_{2} \mathrm{Si}$ phases (see Fig. 4a). Apart from these three identified 
phases, small peaks corresponding to the hexagonal $\mathrm{TiB}_{2}$ phase appear in the XRD patterns of the composite powder and deposits (see Fig. 4b). There was no obvious difference in the XRD patterns between the initial powder and the as-sprayed and annealed samples within the limitation of the XRD detection, indicating no formation of new phases during CS deposition and heat treatments. Moreover, the XRD patterns reveal that the intensity of the Si peaks increases with the increase of the annealing temperature. This observation suggests a reduction of Si solid solubility in the $\mathrm{Al}$ matrix after the high-temperature annealing treatments. This could be mainly explained by the precipitation of $\mathrm{Si}$ particles out from the $\mathrm{Al}$ matrix after annealing treatment.

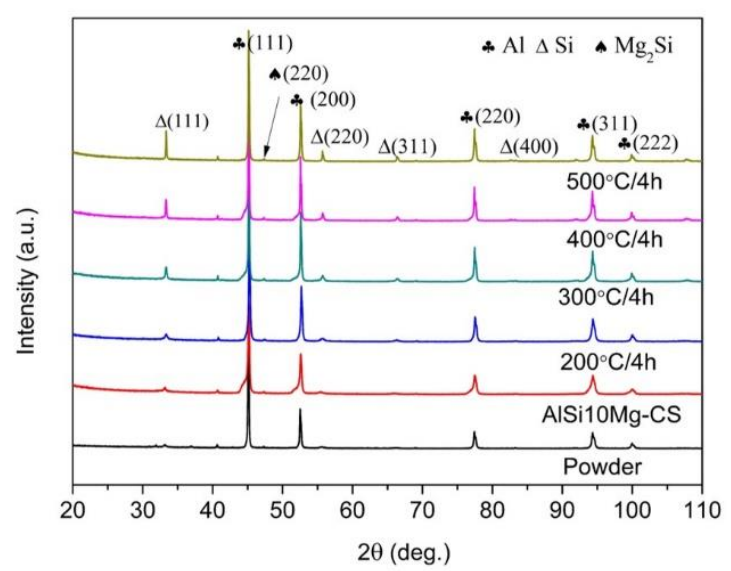

(a)

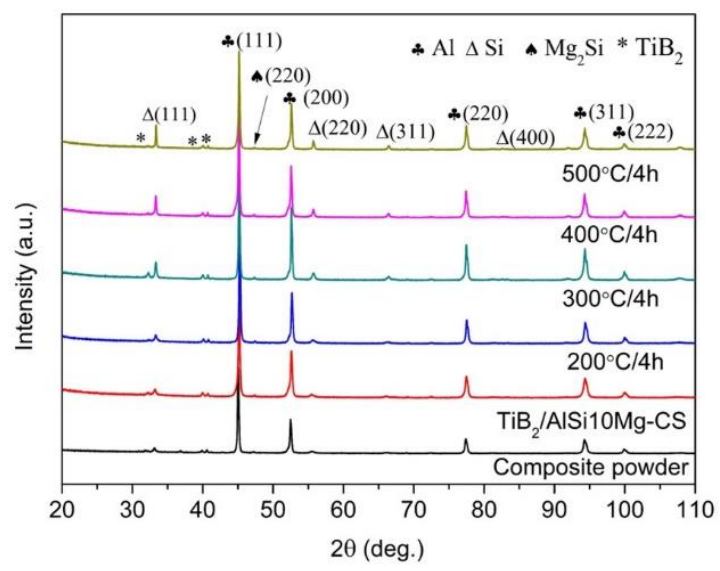

(b)

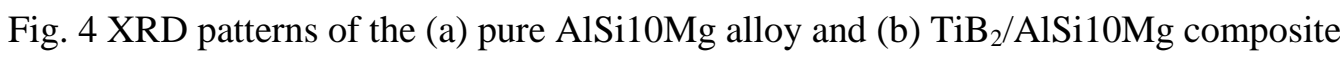
including initial powders, as-sprayed and post-annealed specimens.

\subsection{Microstructure evolution}

Fig. $5 \mathrm{a}$ and $\mathrm{b}$ show the cross-sectional micrographs of the as-sprayed pure AlSi10Mg and $\mathrm{TiB}_{2} / \mathrm{AlSi10Mg}$ composite deposits, respectively. A few small pores with a size of less than 2 $\mu \mathrm{m}$ can be seen on the polished surface of the as-sprayed deposits. The porosity measurements yield average values of $0.35 \%$ and $0.24 \%$ for the pure AlSi10Mg and composite deposits, respectively. Interestingly, the composite deposit possesses slightly lower porosity compared to the pure $\mathrm{AlSi} 10 \mathrm{Mg}$ sample. It can be seen from Fig. $5 \mathrm{a}$ and $\mathrm{b}$ that, the fine $\mathrm{TiB}_{2}$ particles as well as some micron-sized $\mathrm{TiB}_{2}$ clusters are dispersed across the composite deposits. The size of $\mathrm{TiB}_{2}$ particles ranges from $100 \mathrm{~nm}$ to $6 \mu \mathrm{m}$, while most of them are smaller than $500 \mathrm{~nm}$. By analyzing five SEM images, the volume content of $\mathrm{TiB}_{2}$ particles in the composite deposits yields around $3.2 \mathrm{vol} . \%$. It should be noted that the $\mathrm{TiB}_{2}$ particles with a size of less than 100 $\mathrm{nm}$ are not detectable using SEM images. The structure and content of $\mathrm{TiB}_{2}$ particles in the initial composite powder are well maintained in the CS composite deposits. 
The etched morphologies of the as-sprayed deposits (Fig. 5c and d) display a highly deformed structure with some poorly bonded interfaces and micro-pores located at the intersplat boundaries. The magnified SEM views in Fig. 5e and f show grey primary $\alpha$-Al structure decorated with white fibrous Si networks, which is similar to the structure of the initial powder. Some fibrous-like Si networks are heavily deformed, forming linear arrayed ultrafine $\mathrm{Si}$ particles, especially for those located at the inter-splat boundary regions.
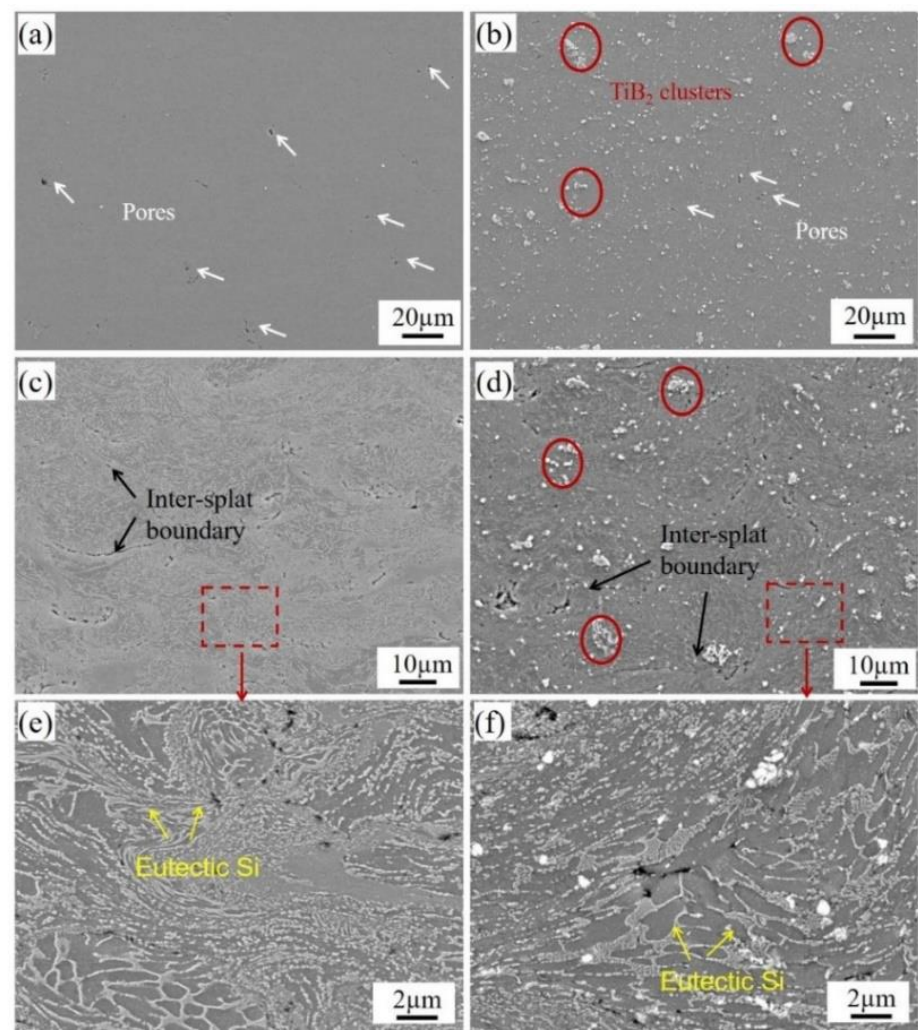

Fig. 5 Cross-sectional morphologies of the CS (a, c) AlSi10Mg and (b, d) TiB $2 / \mathrm{AlSi10Mg}$ composite deposits. (e) and (f) are the magnified images of marked regions in (c) and (d), respectively.

Fig. 6 shows the cross-sectional morphologies of the deposits obtained by SEM. Pores (marked by white arrows) become less visible as the annealing temperature increases to 300 ${ }^{\circ} \mathrm{C}$. Interestingly, increased pores with a large size $(>20 \mu \mathrm{m})$ are presented on the cross-section of the samples annealed at $500^{\circ} \mathrm{C}$. The measured porosity evolution of the deposits as a function of annealing temperature is illustrated in Fig. 7. The porosity values of both deposits decrease slightly as the annealing temperature increases from $200^{\circ} \mathrm{C}$ to $300^{\circ} \mathrm{C}$, and then increase slightly when the annealing temperature is further increased to $400{ }^{\circ} \mathrm{C}$, followed by a sharp increase to $\sim 2.6 \%$ at $500{ }^{\circ} \mathrm{C}$. For each annealing temperature, the $\mathrm{TiB}_{2} / \mathrm{AlSi} 10 \mathrm{Mg}$ composite sample exhibits a slightly lower porosity level compared to the pure AlSi10Mg sample. 
The microstructure evolution of the deposits is presented in Fig. 8. When the samples were annealed at $200{ }^{\circ} \mathrm{C}$ for $4 \mathrm{~h}$, inter-splat boundaries are still clearly observed on the cross-sectional micrographs of both the pure $\mathrm{AlSi} 10 \mathrm{Mg}$ and $\mathrm{TiB}_{2} / \mathrm{AlSi} 10 \mathrm{Mg}$ composite samples, as illustrated in Fig. $8 \mathrm{a}$ and e. Few structural changes are found compared to the as-sprayed states. When increasing the annealing temperature to $300^{\circ} \mathrm{C}$, as shown in Fig. $8 \mathrm{~b}$ and $\mathrm{f}$, the tightly bonded inter-splat boundaries disappear, but some poorly bonded regions can still be observed. It seems that effective diffusion between the particle interface only happens with the close cohesion of particles. As the annealing temperature is increased to $400^{\circ} \mathrm{C}$, most of the inter-splat boundaries become obscure and discontinuous with only a few poorly bonded interfaces left. Further increasing the annealing temperature to $500{ }^{\circ} \mathrm{C}$ leads to no inter-splat boundaries, but apparent porosities. This proves a remarkable atomic diffusion process between the particle interfaces at higher annealing temperatures.
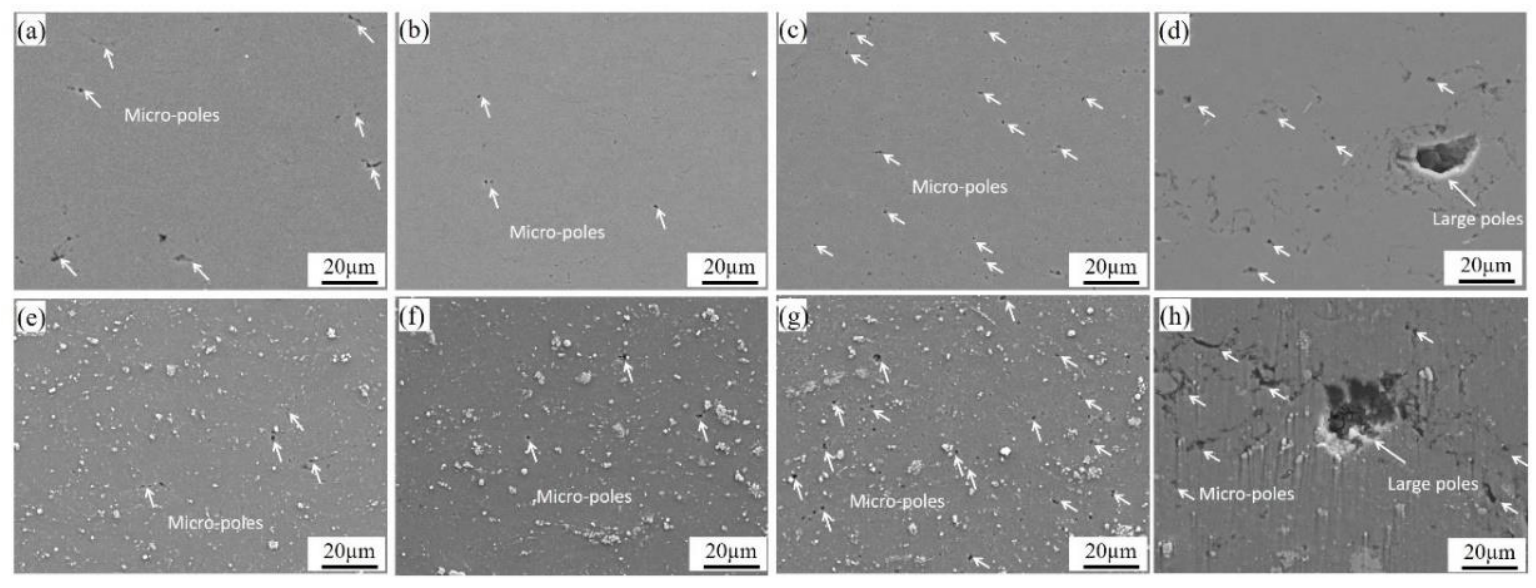

Fig. 6 Cross-sectional morphologies of the annealed (a-d) AlSi10Mg and (e-h)

$\mathrm{TiB}_{2} / \mathrm{AlSi} 10 \mathrm{Mg}$ composite coatings at different temperatures: (a) and (e) $200{ }^{\circ} \mathrm{C}$; (b) and (f)

$$
300{ }^{\circ} \mathrm{C} \text {; (c) and (g) } 400{ }^{\circ} \mathrm{C} \text {; (d) and (h) } 500{ }^{\circ} \mathrm{C} \text {. }
$$

The magnified views of the annealed deposits are shown in Fig. 9. Similar to the microstructure of the as-sprayed deposit, the samples annealed at $200{ }^{\circ} \mathrm{C}$ are characterized by ultrafine Si networks inside the less deformed particle while linear alignment of Si particles in highly deformed regions. After annealing at $300{ }^{\circ} \mathrm{C}$ for $4 \mathrm{~h}$, the eutectic network structure is broken into inconsecutive small Si particles. Si particles are getting more and more coarser when increasing the annealing temperature from $400{ }^{\circ} \mathrm{C}$ to $500{ }^{\circ} \mathrm{C}$. Detailed image analysis on several SEM images (Fig. 10) illustrates that when the as-sprayed samples are annealed at 300 ${ }^{\circ} \mathrm{C}$ for $4 \mathrm{~h}$, most of the Si particles are smaller than $0.5 \mu \mathrm{m}$. When increasing the annealing temperature from $400{ }^{\circ} \mathrm{C}$ to $500{ }^{\circ} \mathrm{C}$, Si particles become coarser with their diameter increased from $0.9 \mu \mathrm{m}$ to $1.6 \mu \mathrm{m}$. Also, these coarsened Si particles are uniformly distributed in the $\mathrm{Al}$ matrix. A decrease in Si particle number accompanied the increase in particle size caused by 
Ostwald ripening. As can be seen from Fig. 10, Si particle density decreased from 14.4 particles $/ \mu \mathrm{m}^{2}$ to 0.23 particles $/ \mu \mathrm{m}^{2}$. A similar tendency on Si particle size and particle density can also be observed in the $\mathrm{TiB}_{2} / \mathrm{AlSi10Mg}$ composite deposits. The as-sprayed samples inherit a microstructure of initial powder, consisting of a supersaturated Al matrix decorated with fibrous eutectic Si particles. After annealing treatment, the eutectic Si is rejected from the supersaturated $\mathrm{Al}$ to form small individual $\mathrm{Si}$ particles. With the increase of annealing temperature, individual Si particles generally precipitate on $\mathrm{Al}$ the matrix and grow up with their number decreased remarkably.

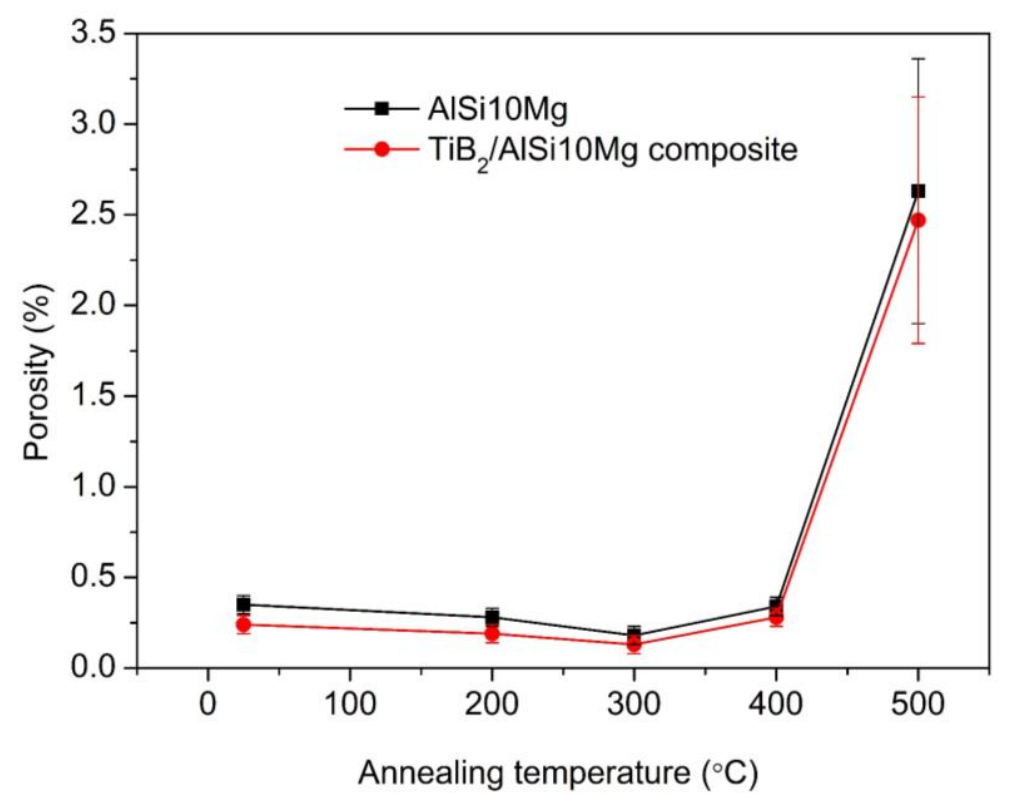

Fig. 7 Porosity evolution of the AlSi10Mg and $\mathrm{TiB}_{2} / \mathrm{AlSi} 10 \mathrm{Mg}$ composite deposits after heat treatment.
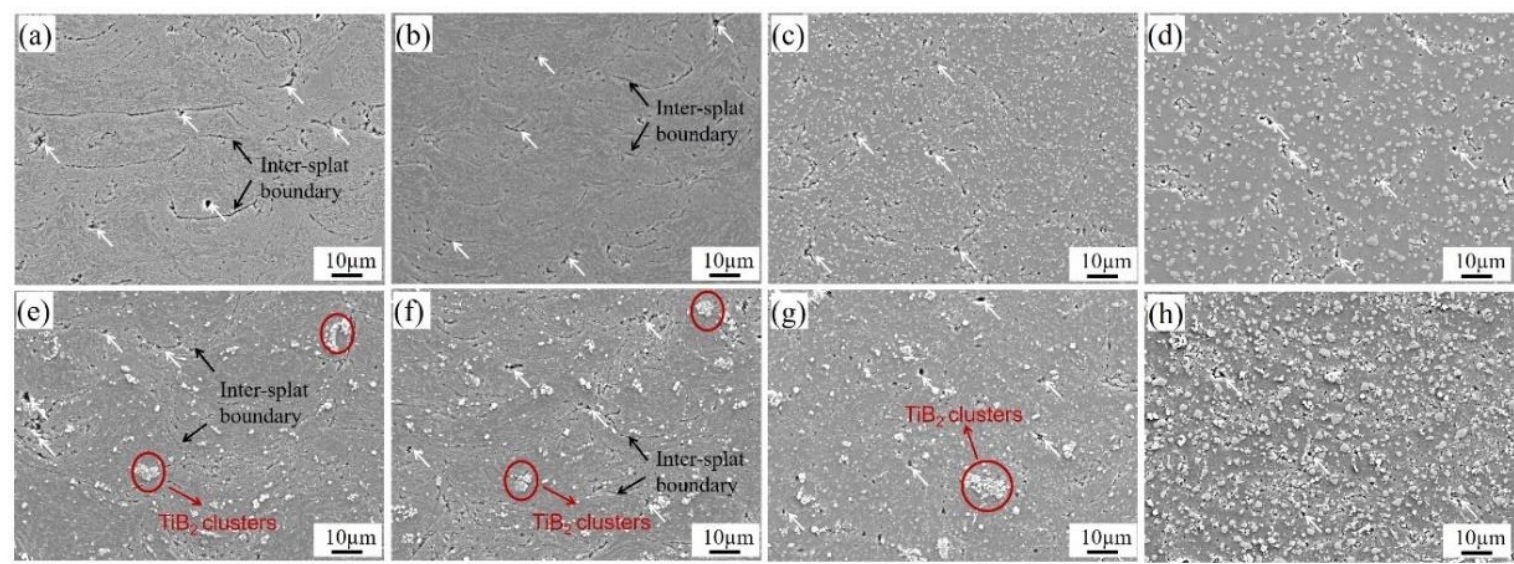

Fig. 8 SEM micrographs of the etched cross-sections of the annealed (a-d) AlSi10Mg and (e-

h) $\mathrm{TiB}_{2} / \mathrm{AlSi} 10 \mathrm{Mg}$ composite samples at a lower magnification: (a) and (e) $200{ }^{\circ} \mathrm{C}$; (b) and (f)

$$
300{ }^{\circ} \mathrm{C} \text {; (c) and (g) } 400{ }^{\circ} \mathrm{C} \text {; (d) and (h) } 500{ }^{\circ} \mathrm{C} \text {. }
$$




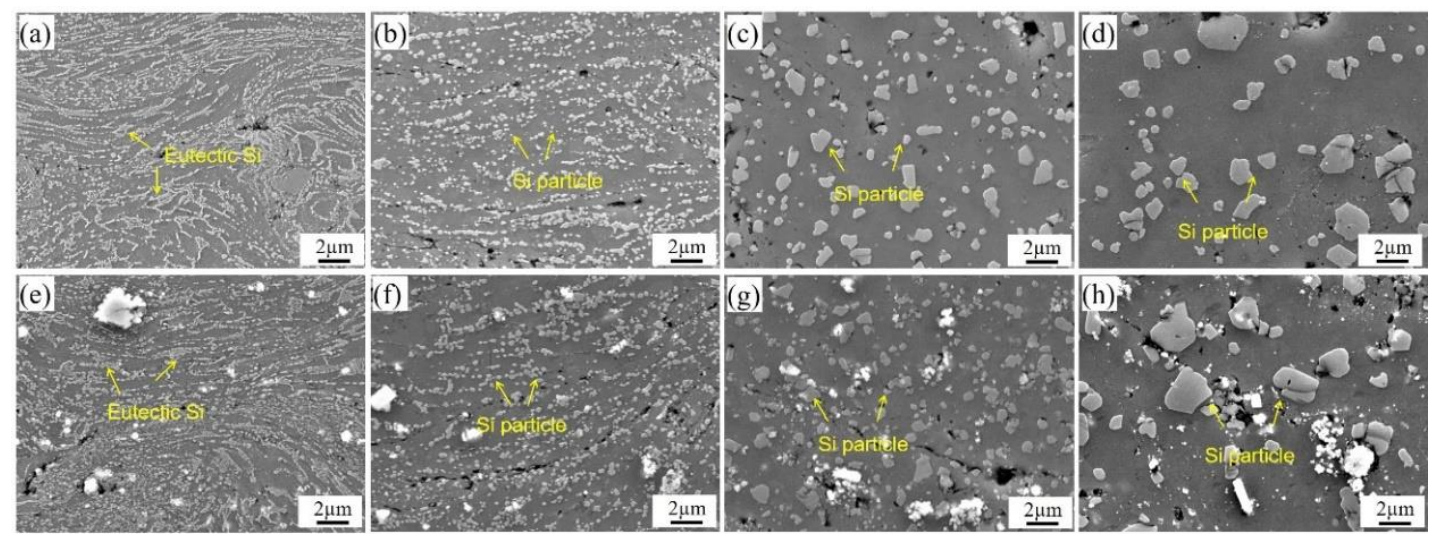

Fig. 9 Cross-sectional morphologies (higher magnification) of the annealed (a-d) AlSi10Mg and (e-h) $\mathrm{TiB}_{2} / \mathrm{AlSi} 10 \mathrm{Mg}$ composite deposits: (a) and (e) $200{ }^{\circ} \mathrm{C}$; (b) and (f) $300{ }^{\circ} \mathrm{C}$; (c) and (g) $400{ }^{\circ} \mathrm{C}$; (d) and (h) $500{ }^{\circ} \mathrm{C}$.

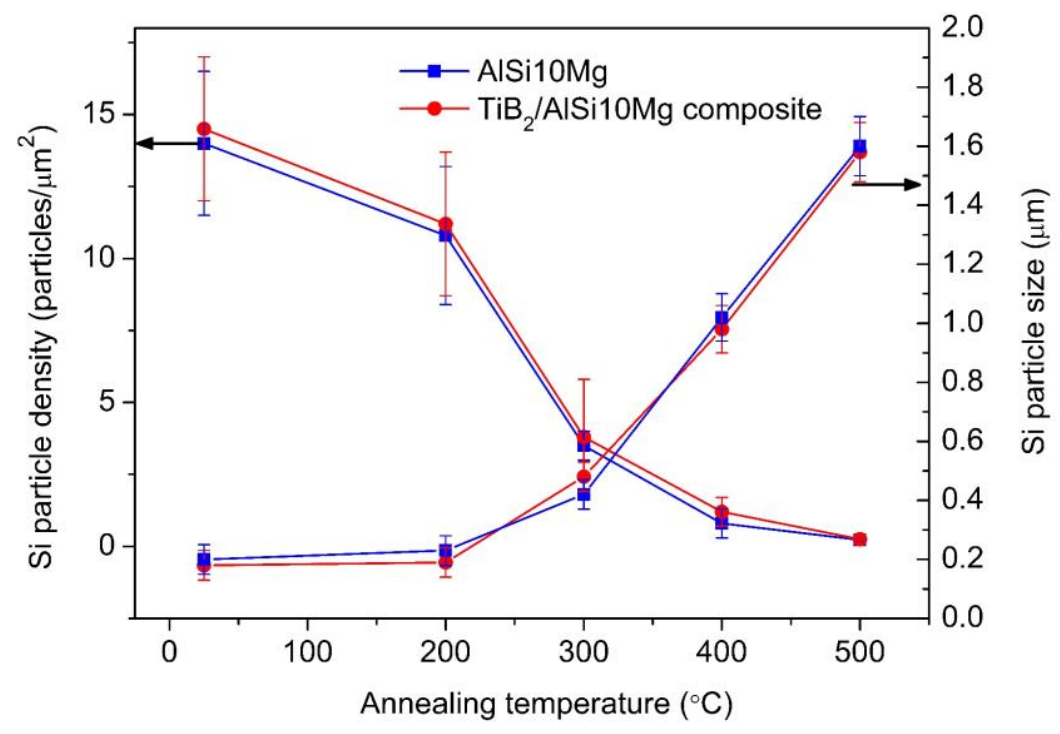

Fig. 10 Si particle density and particle size evolution as a function of annealing temperatures.

SEM/EBSD characterization was carried out to further analyze the grain structure evolution of the CS samples. In the as-sprayed state (Fig. 11a and e), both the pure AlSi10Mg and $\mathrm{TiB}_{2} / \mathrm{AlSi10Mg}$ composite samples are characterized by a bimodal structure with ultrafine grains located at the highly deformed inter-splat regions. This observation is confirmed by TEM. As shown in Fig. 13a and b, ultrafine equiaxed grains with a size less than $150 \mathrm{~nm}$ are formed near the inter-splat boundaries. These ultrafine gains formed mainly due to the dynamic recrystallization induced by high strain rate plastic deformation during CS deposition [9]. Both the pure $\mathrm{AlSi} 10 \mathrm{Mg}$ and $\mathrm{TiB}_{2} / \mathrm{AlSi} 10 \mathrm{Mg}$ composite deposits yield an average grain size of around $1.3 \mu \mathrm{m}$. The grain sizes of both CS samples show a slight increase at the low annealing temperature of $300{ }^{\circ} \mathrm{C}$, but a remarkable increase when the annealing temperature exceeds 
$400^{\circ} \mathrm{C}$. The composite samples have smaller grain size compared to the pure AlSi10Mg sample, and this difference is much evident in the cases of high-temperature annealing treatment. This observation indicates that the addition of dispersed $\mathrm{TiB}_{2}$ nanoparticles can effectively inhibit grain growth during heat treatment. TEM images in Fig. $13 \mathrm{c}$ and $\mathrm{d}$ reveal that the nano-sized $\mathrm{TiB}_{2}$ particles primarily distribute along grain boundaries, while the Si particles disperse not only along the grain boundaries but also inside the grain cells in the as-sprayed composite deposit.

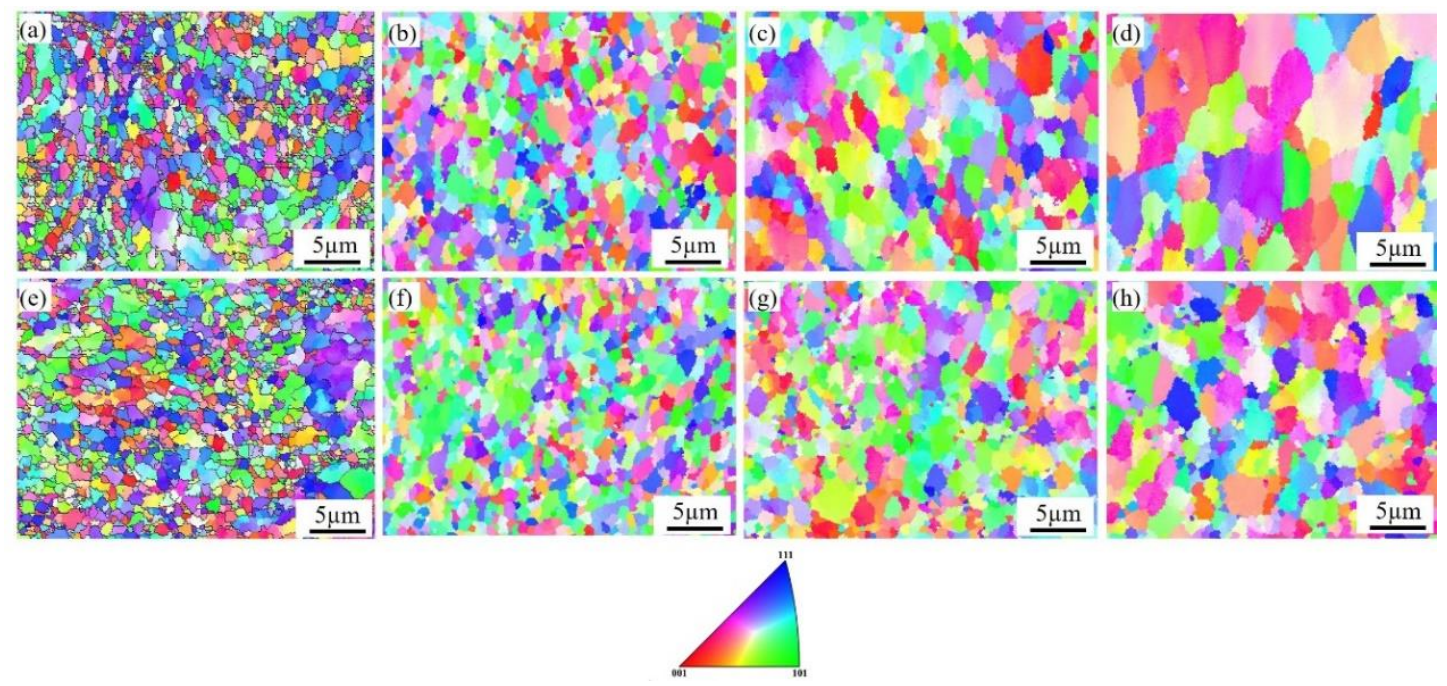

Fig. 11 IPF maps of the (a-d) pure AlSi10Mg and (e-h) $\mathrm{TiB}_{2} / \mathrm{AlSi10Mg}$ composite samples in the (a, e) as-sprayed state and after annealing treatment at (b, f) $300{ }^{\circ} \mathrm{C} ;(\mathrm{c}, \mathrm{g}) 400{ }^{\circ} \mathrm{C} ;(\mathrm{d}, \mathrm{h})$ $500{ }^{\circ} \mathrm{C}$ for $4 \mathrm{~h}$.

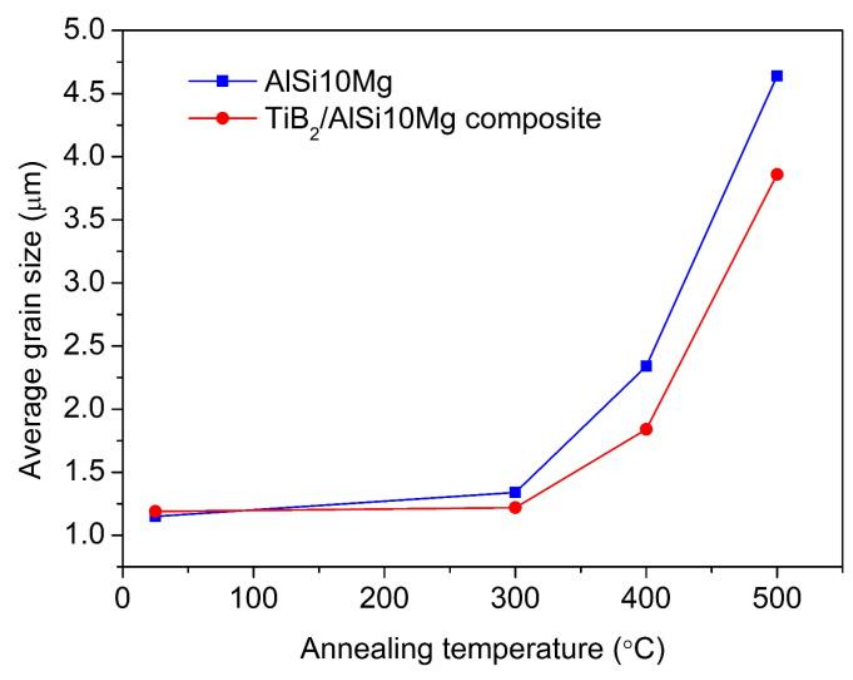

Fig. 12 Average grain size evolution as a function of annealing temperature. 

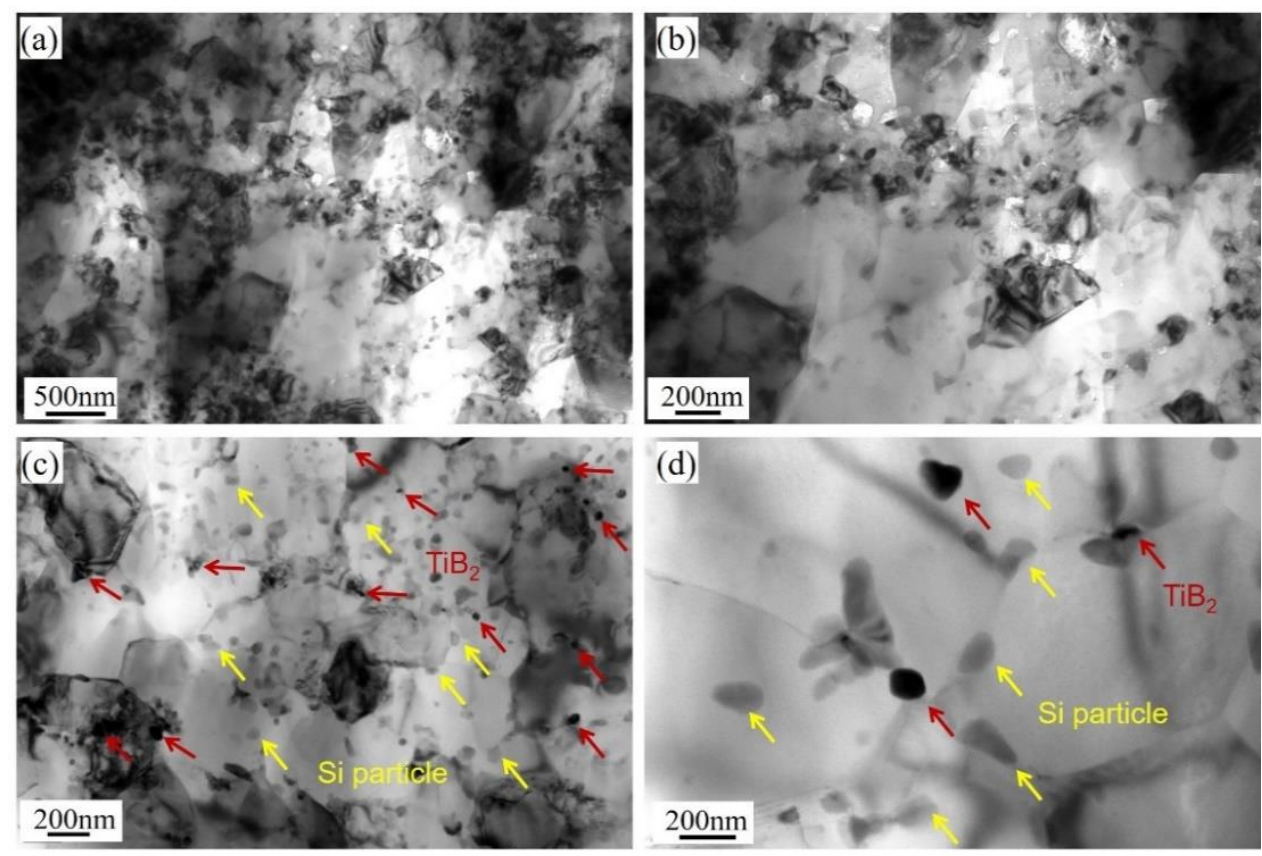

Fig. 13 TEM bright-filed images showing the (a) recrystallized grains and (c) dispersed $\mathrm{TiB}_{2}$ and Si particles in the $\mathrm{CS} \mathrm{TiB}_{2} / \mathrm{AlSi} 10 \mathrm{Mg}$ composite sample. (b) and (d) are magnified views.

\subsection{Microhardness evolution}

Fig. 14 shows the microhardness evolution of the CS pure AlSi10Mg and $\mathrm{TiB}_{2} / \mathrm{AlSi} 10 \mathrm{Mg}$ composite samples as a function of annealing temperature. The microhardness of the as-sprayed AlSi10Mg deposit is about $140 \pm 4 \mathrm{HV}_{0.1}$, which is much higher than that of the as-cast AlSi10Mg parts $\left(67 \mathrm{HV}_{0.1}\right)$ [53]. The as-sprayed composite sample reaches a higher value of $180 \pm 5 \mathrm{HV}_{0.1}$, showing around $29 \%$ increment compared to the pure AlSi10Mg deposit. After annealing treatment, the microhardness demonstrates a gentle decrement at low annealing temperature but a sharp drop when the annealing temperature increased to $300^{\circ} \mathrm{C}$ (Fig. 14). The composite deposit possesses higher microhardness compared to the pure AlSi10Mg samples due to the reinforcement of $\mathrm{TiB}_{2}$ particles and the finer grain size. 


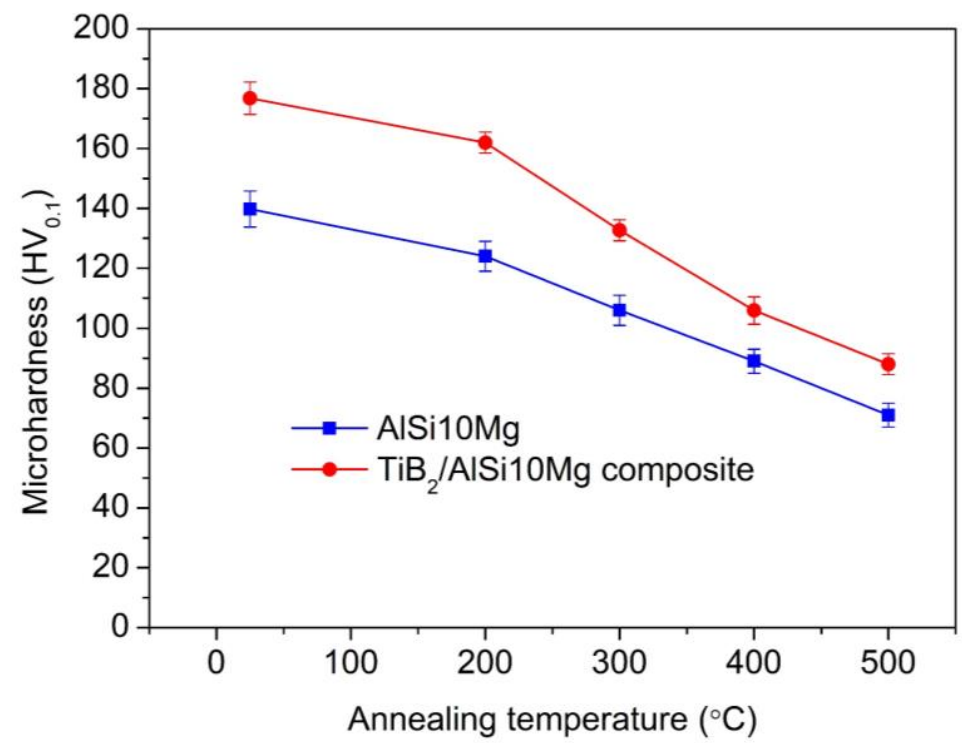

Fig. 14 Microhardness evolution of the as-sprayed AlSi10Mg and $\mathrm{TiB}_{2} / \mathrm{AlSi} 10 \mathrm{Mg}$ composite deposits as a function of annealing temperature.

\subsection{Tensile properties}

Fig. 15a shows representative stress-strain curves of the CS pure AlSi10Mg and $\mathrm{TiB}_{2} / \mathrm{AlSi10Mg}$ composite deposits before and after heat treatments. The ultimate tensile strength (UTS) and elongation values are summarized in Fig. 15b and c, respectively. Both the pure AlSi10Mg and $\mathrm{TiB}_{2} / \mathrm{AlSi} 10 \mathrm{Mg}$ composite deposits exhibit high UTS values but almost no ductility in the as-sprayed state, which implies the typical brittle behavior of the CS deposits $[11,24,28,29,49,54-56]$. However, it can be noted that the as-sprayed composite sample fractured at an earlier stage and has lower tensile strength compared to the pure AlSil0Mg deposit, even though the composite deposit possesses a denser structure and a much higher microhardness. The brittleness of CS samples in the as-sprayed state is notably improved by introducing annealing treatments. After annealing at $300{ }^{\circ} \mathrm{C}$ for $4 \mathrm{~h}$, the UTS values of the pure AlSi10Mg and $\mathrm{TiB}_{2} / \mathrm{AlSi} 10 \mathrm{Mg}$ composite deposits decrease from $410 \mathrm{MPa}$ and $354 \mathrm{MPa}$ to $276 \mathrm{MPa}$ and $337 \mathrm{MPa}$, respectively, while the elongation value increase from $0.4 \%$ and $0.7 \%$ to $4.3 \%$ and $3.2 \%$, respectively. As the annealing temperature increases to $400{ }^{\circ} \mathrm{C}$, further improvement in ductility but a significant decrease in UTS values for both deposits can be observed. The elongation of the pure AlSi10Mg sample reaches $12.0 \pm 0.4 \%$, while the composite has an elongation value of $7.6 \pm 0.4 \%$. As the annealing temperature further increases to $500{ }^{\circ} \mathrm{C}$, the specimens, especially for the pure AlSi10Mg sample, are fractured much earlier with lower UTS and elongation values compared to the samples annealed at $400{ }^{\circ} \mathrm{C}$. This 
phenomenon should be explained by the formation of large pores in the deposits after the hightemperature annealing.

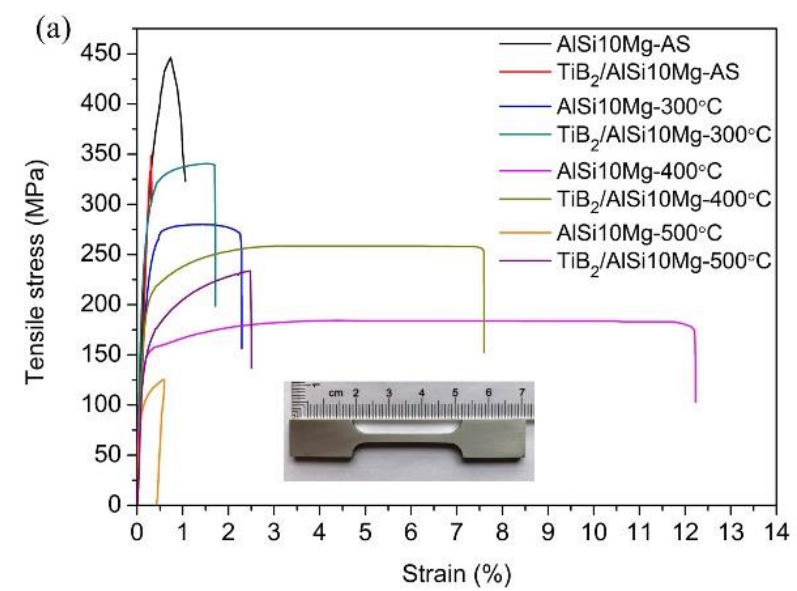

(b)

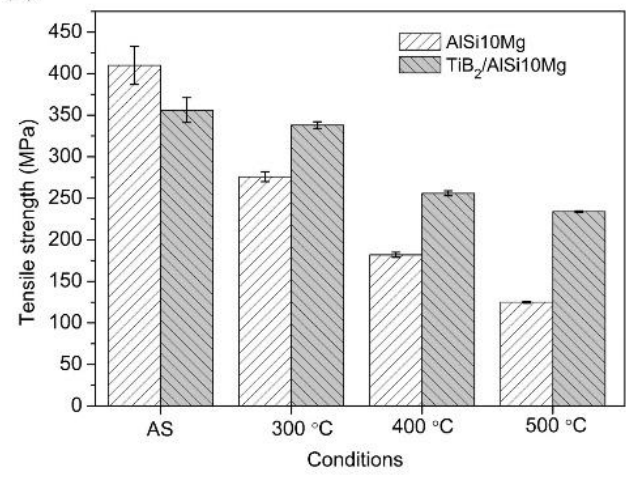

(c)

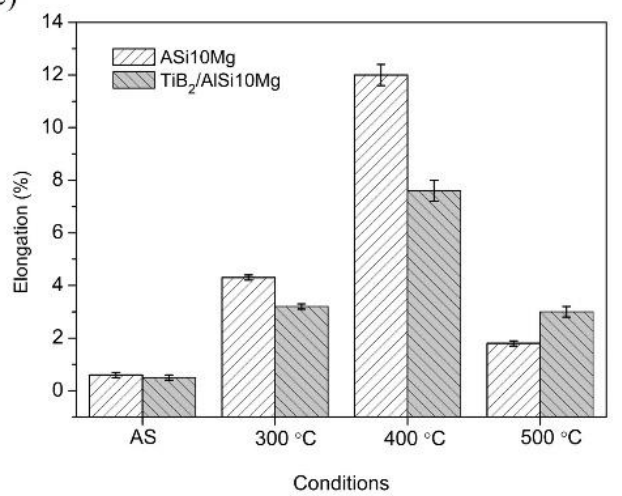

Fig. 15 (a) Tensile stress-strain curves of the pure AlSi10Mg and $\mathrm{TiB}_{2} / \mathrm{AlSi} 10 \mathrm{Mg}$ composites in as-sprayed state and annealing treated at different temperatures. The corresponding UTS and elongation values are summarized in (b) and (c), respectively.

SEM observation of the fracture morphologies of the AlSi10Mg and $\mathrm{TiB}_{2} / \mathrm{AlSi} 10 \mathrm{Mg}$ composite samples after the tensile test are shown in Fig. 16. As can be seen from Fig. 16a and e, both the as-sprayed samples are primarily fractured along interparticle interfaces. The entire morphology of the as-sprayed samples demonstrates a brittle feature, even though a few fine dimples can be observed in some highly deformed regions. Moreover, the fracture surface presents some craters, which are formed by plucking out the entire particles. Comparatively, more large craters (traces of detached particles) are formed on the fracture surface of the composite sample (Fig. 16e). As revealed by EDS mapping (Fig. 17), there are some $\mathrm{TiB}_{2}$ clutters present at the fracture surface.

Fig. $16 \mathrm{~b}$ and $\mathrm{f}$ show the fracture morphologies of the samples annealed at $300{ }^{\circ} \mathrm{C}$ for $4 \mathrm{~h}$. Both small dimples and regular cleavage interfaces can be observed on the fracture surface. 
The dimples have a size of approximately $1 \mu \mathrm{m}$, which is indicative of a ductile fracture. However, some defects, such as pores and craters, can still be observed on the fracture surface, indicating insufficient healing of splat boundaries, triple junctions, and other defects in this condition. As the annealing temperature increases to $400{ }^{\circ} \mathrm{C}$, the fracture surface is dominated by small dimples, suggesting a ductile model. Further increasing the annealing temperature to $500{ }^{\circ} \mathrm{C}$ leads to enlarged dimples $(3-4 \mu \mathrm{m})$ but evident large interior pores on the fracture surfaces (Fig. 16d and h). Similar fracture morphologies can be found in both the pure AlSi10Mg and $\mathrm{TiB}_{2} / \mathrm{AlSi} 10 \mathrm{Mg}$ deposits at high annealing temperatures.
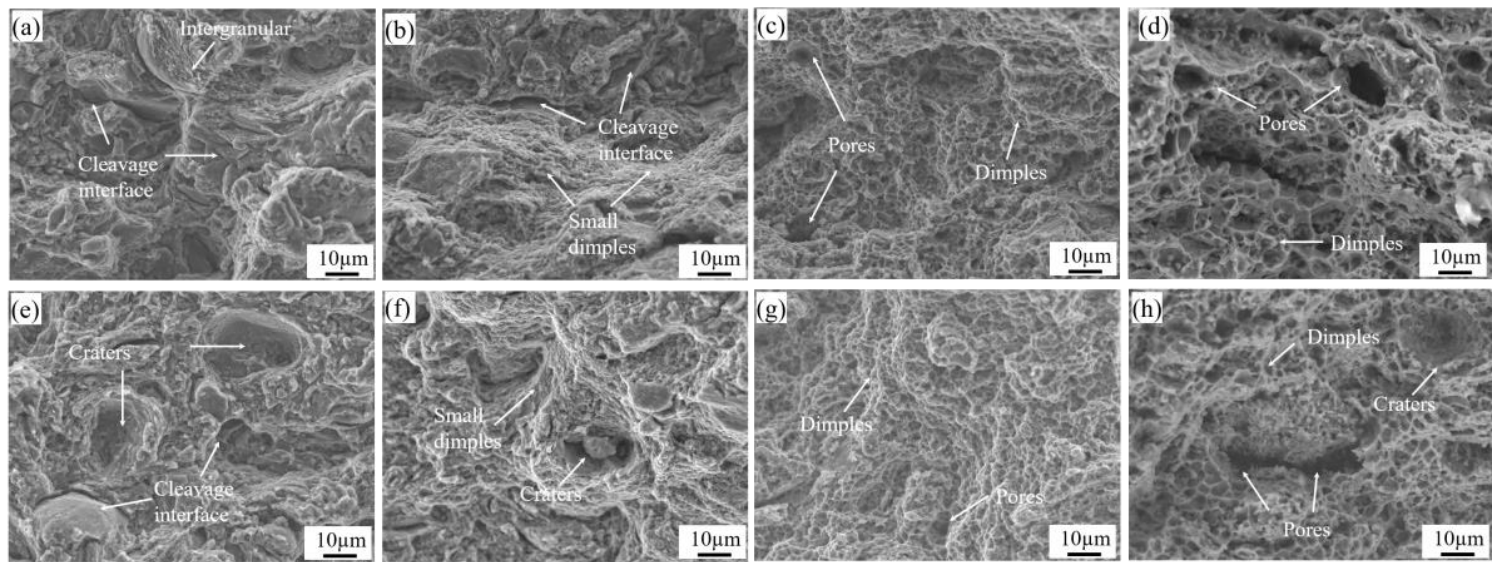

Fig. 16 Fracture morphologies of the (a-d) pureAlSi10Mg and (e-h) $\mathrm{TiB}_{2} / \mathrm{AlSi10Mg}$ composite deposits after the tensile test: (a, e) as-sprayed state; (b, f) $300{ }^{\circ} \mathrm{C} ;(\mathrm{c}, \mathrm{g}) 400{ }^{\circ} \mathrm{C} ;(\mathrm{d}$,

h) $500{ }^{\circ} \mathrm{C}$
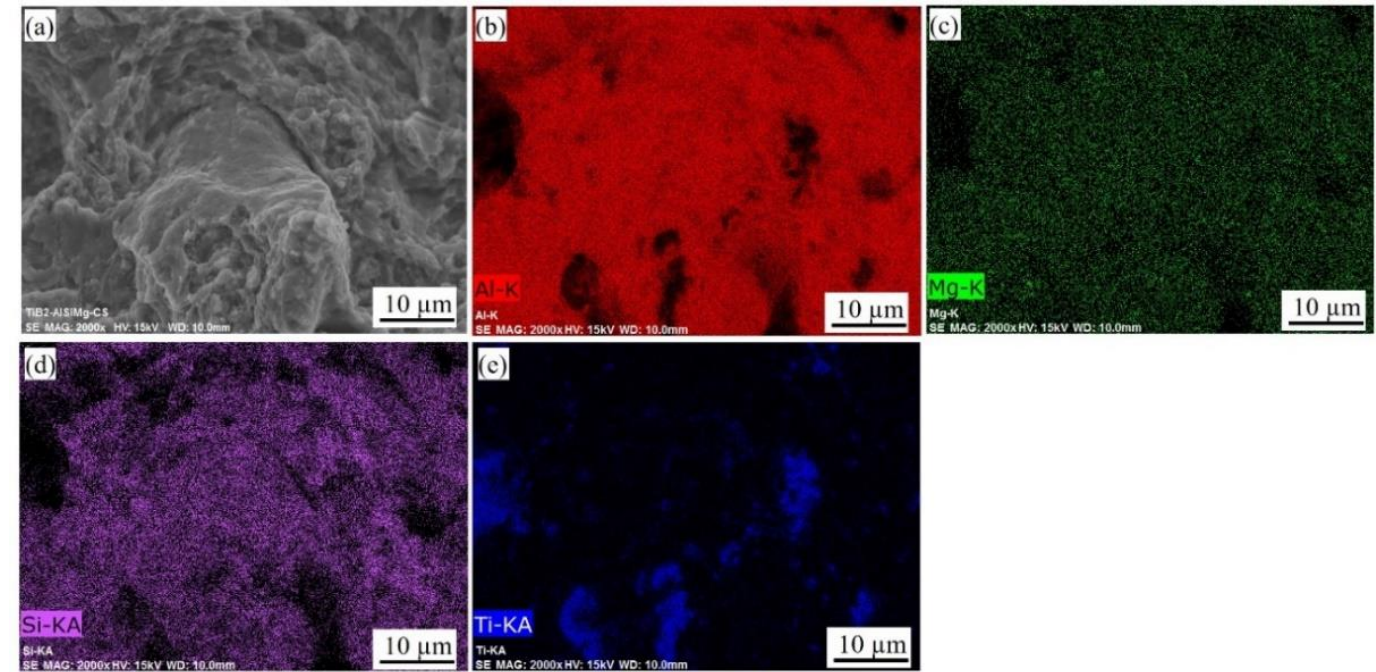

Fig. 17 Fracture morphologies and the corresponding EDS mapping of the CS

$\mathrm{TiB}_{2} / \mathrm{AlSi} 10 \mathrm{Mg}$ composite sample. The element Ti represents the distribution of $\mathrm{TiB}_{2}$

particles. 


\section{Discussions}

\subsection{Effect of annealing treatment on porosity evolution}

Our experimental results show that near fully dense structures (porosity values less than $<0.5 \%$ ) were successfully obtained in both the CS pure AlSi10Mg and $\mathrm{TiB}_{2} / \mathrm{AlSi} 10 \mathrm{Mg}$ composite samples due to the intense plastic deformation of each particle during CS deposition. Compared to the pure AlSi10Mg sample, the $\mathrm{TiB}_{2} / \mathrm{AlSi} 10 \mathrm{Mg}$ composite sample exhibits a lower porosity in the as-sprayed state. The porosity of the CS deposit depends on two aspects: i) plastic deformation of the impact particles and ii) in-situ peening effect of the subsequent particles on previously deposited layers. Since the pure AlSi10Mg and $\mathrm{TiB}_{2} / \mathrm{AlSi} 10 \mathrm{Mg}$ composite particles have similar particle size distribution and impact velocities, the composite particle should be less deformed due to its higher microhardness $\left(68 \pm 4 \mathrm{HV}_{0.015}\right)$ than that of the pure particle ( $52 \pm 4 \mathrm{HV}_{0.015}$ ). Therefore, the reduced porosity of the composite deposit can be explained by the latter factor. On the one hand, the dispersion of $\mathrm{TiB}_{2}$ particles in the AlSi10Mg matrix can strengthen the particles, and higher critical velocity is required for the successful deposition of the composite particles. That is to say, a larger number of composite particles with the impact velocity lower than the critical value cannot be deposited successfully but rebound away from the surface. On the other hand, the presence of $\mathrm{TiB}_{2}$ particles on the composite particle surface may act as contaminants like oxides, which can hinder the metallic bonding between splats during deposition. These two factors together lead to lower deposition efficiency and more rebounded particles, in turn, enhancing the peening effect to the previously deposited layers [57, 58]. Consequently, a slightly denser structure can be obtained in the composite deposits.

It is interesting to note that the porosity of the CS deposits decreases slightly at low annealing temperatures $\left(200{ }^{\circ} \mathrm{C}\right.$ and $\left.300^{\circ} \mathrm{C}\right)$ but increases when the annealing temperature is higher than $400{ }^{\circ} \mathrm{C}$. Particularly, some large pores $(>20 \mu \mathrm{m})$ were obtained when the samples were annealed at $500{ }^{\circ} \mathrm{C}$ for $4 \mathrm{~h}$. On one hand, it is well understood that the recrystallization/recovery and atomic diffusion during low temperature annealing treatment can close some small pores at inter-splat interfaces and reduce the porosity [28, 59]. On the other hand, the aggregation of nano-pores, which are out of account using image method can increase the porosity at high annealing temperatures (higher than $400^{\circ} \mathrm{C}$ ). However, the formation of abnormal large pores at $500{ }^{\circ} \mathrm{C}$ might have some other reasons. One possible reason could be explained by the release of hydrogen at high annealing temperature via a chemical reaction of $\mathrm{Al}$ with moisture, which comes from the initial AlSi10Mg powder. When the $\mathrm{Al}$ alloy powder is exposed to the atmosphere, it is quite easy for these micron-sized particles to absorb moisture on their surface [60]. Since the powders used in this work were stored in air and without drying before CS deposition, the moisture of the powder is likely to be retained in the CS deposits and 
reacts with $\mathrm{Al}$ to produce hydrogen at high temperatures. The enlargement of spherical pores was also reported in the laser powder bed additive manufactured Al-Si alloy parts after hightemperature treatment [61]. The authors claimed that these big pores could be explained by the moisture of the powder and hydrogen release after heat treatment [61]. More research work will be carried out to further confirm our hypothesis in the near future. Nevertheless, these pores could largely degrade the final mechanical performance of the CS deposits.

\subsection{Relationship between the microstructure evolution and mechanical properties}

In the as-sprayed state, the recrystallized fine grains and enhanced work hardening effect induced by intensive plastic deformation result in high microhardness and tensile strength. Nevertheless, there are still some micro-pores and poorly bonded interfaces within the deposit, which can significantly degrade the tensile properties. As revealed by the fracture morphology of the as-sprayed samples (Fig. 16a and e), it is dominated by cleavage fracture through weakly bonded interparticle boundaries as well as an intergranular fracture. According to Yu et al. [62], the formation of nanocrystalline grains in the intensively deformed inter-splat regions as a result of recovery or dynamic recrystallization has very limited ductility. Once the crack starts from the pores or poorly bonded regions, it can propagate along these nanocrystalline grains, resulting in a cleavage fracture. Moreover, it was reported that the size and morphology of the eutectic $\mathrm{Si}$ particles and reinforced particles have an important impact on the fracture performance of the Al-Si alloys [63, 64]. According to Li et al. [64], the presence of $\mathrm{TiB}_{2}$ clusters and Si networks at the GBs can cause localized shearing to occur and hence lead to the crack initiation and propagation. The presence of some $\mathrm{TiB}_{2}$ clusters on the deformed splats surface may also give rise to the formation of these craters. As revealed by EDS mapping of the fracture surface (Fig. 17), these $\mathrm{TiB}_{2}$ clutters act as contaminants, preventing the metallic bonding in these areas. As a result, fracture occurred easily in these weakly bonded regions. This phenomenon can explain the lower strength of the as-sprayed composite samples in comparison to the pure AlSi10Mg samples. Indeed, premature fracture is a critical problem for the CS metallic components. In the as-sprayed state, as illustrated in Fig. 18a and b, the presence of defects including micro-pores and poorly bonded interfaces, nanocrystalline and Si network structure, as well as the $\mathrm{TiB}_{2}$ clusters could facilitate fracture of the composite during tensile test.

According to Li et al. [65], annealing treatment can affect the interface bonding of the deformed Al particles, recrystallization, grain growth and work hardening effect generated during CS deposition, while little effect on the sizes, morphologies and distribution of the reinforced particles (TiN) was found in the CS TiN/5056Al composite. The dispersion of reinforced particles plays a greater role in strengthening the CS Al composite than the strain hardening effect of TiN tamping on the Al matrix after annealing treatment [66]. In this study, 
annealing treatment was applied to improve the mechanical performance of the CS $\mathrm{TiB}_{2} / \mathrm{AlSi} 10 \mathrm{Mg}$ composites by reducing defects (e.g. micro-pores) and strengthening the intersplat bonding through atom diffusion.

As shown in Fig. 8, the inter-splat boundaries were gradually healed via atomic diffusion and static recrystallization when the annealing temperature increased from $200{ }^{\circ} \mathrm{C}$ to $500{ }^{\circ} \mathrm{C}$ for 4h. The observation of numbers of dimples instead of regular cleavage interfaces on the fracture surface after tensile tests further confirms the enhanced metallurgical bonding after annealing treatment. As a result, the annealed samples showed remarkable improvement in ductility. The fracture model after annealing treatment is illustrated in Fig. 18c and d. However, the elimination of the work hardening effect, coarsening of Si particles, and grain growth induced by annealing treatment decrease the microhardness and tensile strength of the samples. It should be noted that the release of work hardening effect is more prominent than grain growth in decreasing the microhardness and tensile strength at low annealing temperatures, while grain growth is much more important at higher annealing temperatures. As revealed by SEM/EBSD results (Fig. 11), the presence of $\mathrm{TiB}_{2}$ nanoparticles can hinder dislocation movement and grain growth during heat treatment, thereby retarding microhardness and strength reduction. The presence of large pores should be responsible for the reduced tensile properties of the samples annealed at $500{ }^{\circ} \mathrm{C}$

(a)

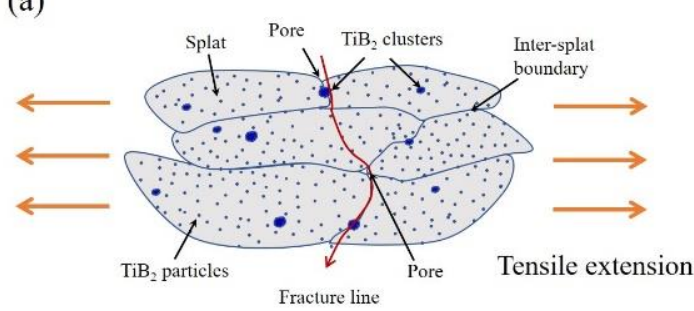

(c)

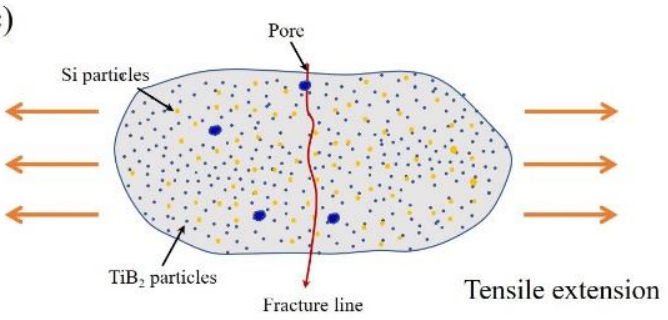

(b)

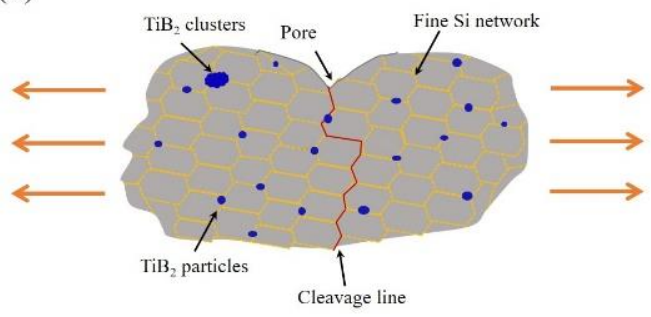

(d)

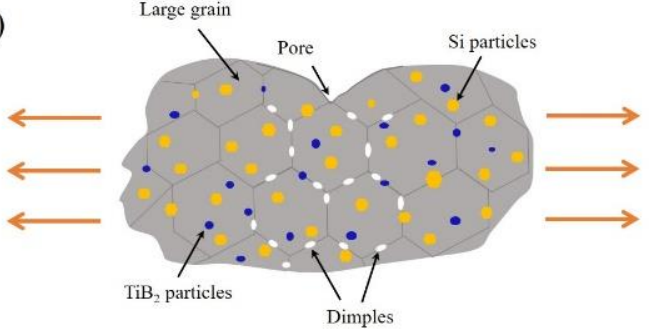

Fig. 18 Schematic of the fractural models of the as-sprayed and annealed composite deposits

(annealing temperature lower than $500^{\circ} \mathrm{C}$ ): fracture model of the as-sprayed composite deposit at (a) micro-scale and (b) submicron-scale; fracture model of the annealed composite deposit at (c) micro-scale and (d) submicron-scale.

Further, it is worth noting that despite the Orowan strengthening [67] and Hall-Petch strengthening effects [68], the in-situ formed $\mathrm{TiB}_{2}$ nanoparticles have a prominent advantage 
in load transfer [69] during fracture compared to the ex-situ ceramic particles reinforced composites produced using mechanical blending mixture due to its favorable high coherency with the Al matrix. Our recent study of the thermo-mechanically treated in-situ $\mathrm{TiB}_{2} / \mathrm{AlZnMgCu}$ composite revealed the semi-coherent $\mathrm{TiB}_{2} / \mathrm{Al}$ interface with the multiple orientation relationships between the facetted surface of $\mathrm{TiB}_{2}$ nanoparticles and $\mathrm{Al}$ matrix [70]. More detailed atomic-scale characterization on of the $\mathrm{TiB}_{2} / \mathrm{Al}$ interface of the as-sprayed and post-annealed samples is also of interest by high-resolution scanning TEM high resolution. Therefore, our study made a step forward to produce high-performance $\mathrm{Al}$ nanocomposite by solid-state CSAM using a specially designed composite powder followed by annealing treatment. Nevertheless, more efforts will be made in the future to further improve the mechanical properties.

\section{Conclusions}

A gas-atomized composite powder reinforced with in-situ $\mathrm{TiB}_{2}$ particles was used as the feedstock to fabricate $\mathrm{TiB}_{2} / \mathrm{AlSi} 10 \mathrm{Mg}$ composite deposit by the cold spray process. Then, the influence of post-annealing treatment on microstructure evolution and mechanical properties was investigated. For comparison, the as-sprayed AlSi10Mg deposits were annealed at the same conditions. The following conclusions can be drawn:

1) The cold sprayed deposits display a fully dense structure with the cellular-like network of eutectic Si particles embedded in the $\mathrm{Al}$ matrix. Apart from the uniformly distributed $\mathrm{TiB}_{2}$ nanoparticles, some clusters on a micrometer scale were also present in the cold sprayed $\mathrm{TiB}_{2} / \mathrm{AlSi} 10 \mathrm{Mg}$ composite deposits. This inhomogeneous distribution of the particles derives from the gas-atomized composite powder.

2) Annealing treatment can heal some micro-pores and improve the inter-splat interface bonding. However, large pores $(>20 \mu \mathrm{m})$ were observed in the samples annealed at $500{ }^{\circ} \mathrm{C}$ for $4 \mathrm{~h}$, probably originated from the moisture of initial $\mathrm{Al}$ alloy powder.

3) The microhardness showed a decreasing trend with the increase in the annealing temperature, mainly due to the elimination of work hardening effect, grain growth, and coarsening of the Si phase. Nevertheless, the composite deposit exhibited an inhabitation of reduction in microhardness because of the hindering effect of the dislocation movement via nanosized hard $\mathrm{TiB}_{2}$ during heat treatment.

4) Both the as-fabricated pure $\mathrm{AlSi} 10 \mathrm{Mg}$ and $\mathrm{TiB}_{2} / \mathrm{AlSi} 10 \mathrm{Mg}$ composite samples exhibited high tensile strength but almost no elongation. Comparatively, relatively lower tensile strength was obtained for the composite samples even though they have a denser structure and higher microhardness than the pure AlSi10Mg deposit. This could be attributed to the presence of $\mathrm{TiB}_{2}$ clusters on the deformed splats surface, which are detrimental for metallic 
bonding between particles, thus resulting in an easier fracture during the tensile test.

5) Significant improvement in ductility accompanied with reduction in strength was obtained for the annealed samples mainly due to the improved interfacial bonding between the deformed splats and grain growth. Besides, the annealed composite samples possess higher strength but lower ductility compared to the unreinforced pure AlSi10Mg samples.

\section{Acknowledgments}

Financial support of X.L. XIE's Ph.D. thesis was from the China Scholarship Council (No. 201604490100). The microscopy facilities in Lille (France) are supported by the Conseil Régional du Nord-Pas de Calais, and the European Regional Development Fund (ERDF).

\section{References}

[1] K M Shorowordi, T Laoui, A Haseeb, JP Celis, L Froyen, Microstructure and interface characteristics of $\mathrm{B} 4 \mathrm{C}, \mathrm{SiC}$ and $\mathrm{Al} 2 \mathrm{O} 3$ reinforced $\mathrm{Al}$ matrix composites: a comparative study, J. Mater. Process. Technol., 142 (2003), 738-743.

[2] L Lü, MO Lai, Y Su, HL Teo, CF Feng, In situ TiB2 reinforced Al alloy composites, Scripta Mater., 45 (2001), 1017-1023.

[3] CS Kim, K Cho, MH Manjili, M Nezafati, Mechanical performance of particulatereinforced $\mathrm{Al}$ metal-matrix composites (MMCs) and $\mathrm{Al}$ metal-matrix nano-composites (MMNCs), J. Mater. Sci., 52 (2017), 13319-13349.

[4] XL Guo, Q Guo, JH Nie, ZY Liu, ZQ Li, GL Fan, DB Xiong, YS Su, JZg Fan, D Zhang, Particle size effect on the interfacial properties of $\mathrm{SiC}$ particle-reinforced $\mathrm{Al}-\mathrm{Cu}-\mathrm{Mg}$ composites, Mater. Sci. Eng., A, 711 (2018), 643-649.

[5] SB Prabu, L Karunamoorthy, S Kathiresan, B Mohan, Influence of stirring speed and stirring time on distribution of particles in cast metal matrix composite, J. Mater. Process. Technol., 171 (2006), 268-273.

[6] S A Sajjadi, HR Ezatpour, H Beygi, Microstructure and mechanical properties of Al-Al2O3 micro and nano composites fabricated by stir casting, Mater. Sci. Eng., A, 528 (2011), 87658771.

[7] M Rahimian, N Parvin, N Ehsani, Investigation of particle size and amount of alumina on microstructure and mechanical properties of $\mathrm{Al}$ matrix composite made by powder metallurgy, Mater. Sci. Eng., A, 527 (2010), 1031-1038.

[8] ZJ Yin, SY Tao, XM Zhou, CX Ding, Microstructure and mechanical properties of Al2O3Al composite coatings deposited by plasma spraying, Appl. Surf. Sci., 254 (2008), 1636-1643.

[9] H Assadi, H Kreye, F Gärtner, T Klassen, Cold spraying-a materials perspective, Acta Mater., 116 (2016), 382-407.

[10] WY Li, CC Cao, S Yin, Solid-state cold spraying of Ti and its alloys: a literature review, Prog. Mater. Sci., (2019), 100633.

[11] S Yin, P Cavaliere, B Aldwell, R Jenkins, HL Liao, WY Li, R Lupoi, Cold spray additive manufacturing and repair: Fundamentals and applications, Addit. Manuf., 21 (2018), 628-650. 
[12] H Assadi, F Gärtner, T Stoltenhoff, H Kreye, Bonding mechanism in cold gas spraying, Acta Mater., 51 (2003), 4379-4394.

[13] M Grujicic, CL Zhao, WS DeRosset, D Helfritch, Adiabatic shear instability based mechanism for particles/substrate bonding in the cold-gas dynamic-spray process, Mater. Des., 25 (2004), 681-688.

[14] YC Xie, S Yin, CY Chen, MP Planche, HL Liao, R Lupoi, New insights into the coating/substrate interfacial bonding mechanism in cold spray, Scripta Mater., 125 (2016), 14.

[15] MR Rokni, SR Nutt, CA Widener, VK Champagne, RH Hrabe, Review of relationship between particle deformation, coating microstructure, and properties in high-pressure cold spray, J. Therm. Spray Technol., 26 (2017), 1308-1355.

[16] WY Li, HL Liao, CJ Li, G Li, C Coddet, XF Wang, On high velocity impact of microsized metallic particles in cold spraying, Appl. Surf. Sci., 253 (2006), 2852-2862.

[17] S Yin, WY Li, B Song, XC Yan, M Kuang, YX Xu, K Wen, R Lupoi, Deposition of FeCoNiCrMn high entropy alloy (HEA) coating via cold spraying, J. Mater. Sci. Technol., 35 (2019), 1003-1007.

[18] S Yin, J Cizek, XC Yan, R Lupoi, Annealing strategies for enhancing mechanical properties of additively manufactured 316L stainless steel deposited by cold spray, Surf. Coat. Technol., (2019),

[19] RN Raoelison, YC Xie, T Sapanathan, MP Planche, R Kromer, S Costil, C Langlade, Cold gas dynamic spray technology: A comprehensive review of processing conditions for various technological developments till to date, Addit. Manuf., 19 (2018), 134-159.

[20] WY Li, K Yang, S Yin, XW Yang, YX Xu, R Lupoi, Solid-state additive manufacturing and repairing by cold spraying: A review, J. Mater. Sci. Technol., 34 (2018), 440-457.

[21] K Yang, WY Li, YX Xu, XW Yang, Using friction stir processing to augment corrosion resistance of cold sprayed AA2024/A12O3 composite coatings, J. Alloys Compd., 774 (2019), 1223-1232.

[22] CY Chen, YC Xie, XC Yan, S Yin, H Fukanuma, RZ Huang, RX Zhao, J Wang, ZM Ren, M Liu, Effect of hot isostatic pressing (HIP) on microstructure and mechanical properties of Ti6Al4V alloy fabricated by cold spray additive manufacturing, Addit. Manuf., 27 (2019), 595605.

[23] RN Raoelison, C Verdy, HL Liao, Cold gas dynamic spray additive manufacturing today: Deposit possibilities, technological solutions and viable applications, Mater. Des., 133 (2017), 266-287.

[24] S Bagherifard, S Monti, M V Zuccoli, M Riccio, J Kondás, M Guagliano, Cold spray deposition for additive manufacturing of freeform structural components compared to selective laser melting, Mater. Sci. Eng., A, 721 (2018), 339-350.

[25] S Yin, R Jenkins, XC Yan, R Lupoi, Microstructure and mechanical anisotropy of additively manufactured cold spray copper deposits, Mater. Sci. Eng., A, 734 (2018), 67-76.

[26] XT Luo, ML Yao, NS Ma, M Takahashi, CJ Li, Deposition behavior, microstructure and mechanical properties of an in-situ micro-forging assisted cold spray enabled additively manufactured Inconel 718 alloy, Mater. Des., 155 (2018), 384-395. 
[27] CY Chen, XCYan, YC Xie, RZ Huang, M Kuang, WY Ma, RX Zhao, J Wang, M Liu, ZM Ren, Microstructure evolution and mechanical properties of maraging steel 300 fabricated by cold spraying, Mater. Sci. Eng., A, 743 (2019), 482-493.

[28] RZ Huang, M Sone, WH Ma, H Fukanuma, The effects of heat treatment on the mechanical properties of cold-sprayed coatings, Surf. Coat. Technol., 261 (2015), 278-288.

[29] S Yin, J Cizek, XC Yan, R Lupoi, Annealing strategies for enhancing mechanical properties of additively manufactured 316L stainless steel deposited by cold spray, Surface and Coatings Technology, 370 (2019), 353-361.

[30] WH Ma, YC Xie, CY Chen, H Fukanuma, J Wang, ZM Ren, RZ Huang, Microstructural and mechanical properties of high-performance Inconel 718 alloy by cold spraying, J. Alloys Compd., 792 (2019), 456-467.

[31] MR Rokni, CA Widener, OC Ozdemir, GA Crawford, Microstructure and mechanical properties of cold sprayed $6061 \mathrm{Al}$ in As-sprayed and heat treated condition, Surf. Coat. Technol., 309 (2017), 641-650.

[32] MR Rokni, CA Widener, VK Champagne, GA Crawford, Microstructure and mechanical properties of cold sprayed 7075 deposition during non-isothermal annealing, Surf. Coat. Technol., 276 (2015), 305-315.

[33] MR Rokni, CA Widener, VK Champagne, GA Crawford, SR Nutt, The effects of heat treatment on $7075 \mathrm{Al}$ cold spray deposits, Surf. Coat. Technol., 310 (2017), 278-285.

[34] M Yandouzi, P Richer, B Jodoin, SiC particulate reinforced Al-12Si alloy composite coatings produced by the pulsed gas dynamic spray process: Microstructure and properties, Surf. Coat. Technol., 203 (2009), 3260-3270.

[35] K Spencer, DM Fabijanic, M-X Zhang, The use of Al-Al2O3 cold spray coatings to improve the surface properties of magnesium alloys, Surface and Coatings Technology, 204 (2009), 336-344.

[36] JM Shockley, HW Strauss, RR Chromik, N Brodusch, R Gauvin, E Irissou, J-G Legoux, In situ tribometry of cold-sprayed Al-Al2O3 composite coatings, Surf. Coat. Technol., 215 (2013), 350-356.

[37] DL Cong, ZS Li, QB He, HB Chen, ZP Zhao, LP Zhang, HL Wu, Wear behavior of corroded Al-Al2O3 composite coatings prepared by cold spray, Surf. Coat. Technol., 326 (2017), 247-254.

[38] Q Wang, N Birbilis, H Huang, MX Zhang, Microstructure characterization and nanomechanics of cold-sprayed pure $\mathrm{Al}$ and $\mathrm{Al}-\mathrm{Al} 2 \mathrm{O} 3$ composite coatings, Surf. Coat. Technol., 232 (2013), 216-223.

[39] X Qiu, JQ Wang, JR Tang, L Gyansah, ZP Zhao, TY Xiong, Microstructure, microhardness and tribological behavior of $\mathrm{Al} 2 \mathrm{O} 3$ reinforced $\mathrm{A} 380$ aluminum alloy composite coatings prepared by cold spray technique, Surface and Coatings Technology, 350 (2018), 391400 .

[40] ZC Zhang, FC Liu, EH Han, L Xu, P C Uzoma, Effects of Al2O3 on the microstructures and corrosion behavior of low-pressure cold gas sprayed Al 2024-Al2O3 composite coatings on AA 2024-T3 substrate, Surface and Coatings Technology, 370 (2019), 53-68.

[41] WY Li, G Zhang, C Zhang, O Elkedim, HL Liao, C Coddet, Effect of ball milling of feedstock powder on microstructure and properties of TiN particle-reinforced $\mathrm{Al}$ alloy-based composites fabricated by cold spraying, J. Therm. Spray Technol., 17 (2008), 316-322. 
[42] M Yu, XK Suo, WY Li, YY Wang, HL Liao, Microstructure, mechanical property and wear performance of cold sprayed Al5056/SiCp composite coatings: effect of reinforcement content, Appl. Surf. Sci., 289 (2014), 188-196.

[43] YY Wang, B Normand, N Mary, M Yu, HL Liao, Effects of ceramic particle size on microstructure and the corrosion behavior of cold sprayed SiCp/Al 5056 composite coatings, Surface and Coatings Technology, 315 (2017), 314-325.

[44] H Chen, Z Pala, T Hussain, DG McCartney, Fabrication and microstrain evolution of AlTiB2 composite coating by cold spray deposition, Proc. Inst. Mech. Eng. L, (2017), 1464420717690559.

[45] O Meydanoglu, B Jodoin, E Sabri Kayali, Microstructure, mechanical properties and corrosion performance of $7075 \mathrm{Al}$ matrix ceramic particle reinforced composite coatings produced by the cold gas dynamic spraying process, Surf. Coat. Technol., 235 (2013), 108-116. [46] DJ Woo, FC Heer, LN Brewer, JP Hooper, S Osswald, Synthesis of nanodiamondreinforced aluminum metal matrix composites using cold-spray deposition, Carbon, 86 (2015), $15-25$.

[47] K Yang, WY Li, CJ Huang, XW Yang, YX Xu, Optimization of cold-sprayed AA2024/A12O3 metal matrix composites via friction stir processing: Effect of rotation speeds, J. Mater. Sci. Technol., (2018),

[48] K Yang, WY Li, CJ Huang, XW Yang, YX Xu, Optimization of cold-sprayed AA2024/A12O3 metal matrix composites via friction stir processing: Effect of rotation speeds, Journal of materials science \& technology, 34 (2018), 2167-2177.

[49] NH Tariq, L Gyansah, JQ Wang, X Qiu, B Feng, MT Siddique, TY Xiong, Cold spray additive manufacturing: A viable strategy to fabricate thick B4C/Al composite coatings for neutron shielding applications, Surf. Coat. Technol., 339 (2018), 224-236.

[50] XL Xie, Y Ma, CY Chen, G Ji, C Verdy, HJ Wu, Z Chen, S Yuan, B Normand, S Yin, Cold spray additive manufacturing of metal matrix composites (MMCs) using a novel nanoTiB2-reinforced 7075Al powder, Journal of Alloys and Compounds, 819 (2020), 152962.

[51] MX Chen, XP Li, G Ji, Y Wu, Z Chen, W Baekelant, K Vanmeensel, HW Wang, JP Kruth, Novel composite powders with uniform TiB2 nano-particle distribution for 3D printing, Applied Sciences, 7 (2017), 250.

[52] EC Santos, M Shiomi, K Osakada, T Laoui, Rapid manufacturing of metal components by laser forming, Int. J. Mach. Tools Manuf., 46 (2006), 1459-1468.

[53] K Zyguła, B Nosek, H Pasiowiec, N Szysiak, Mechanical properties and microstructure of AlSi10Mg alloy obtained by casting and SLM technique, World Scientific News, 104 (2018), 462-472.

[54] A Christopher Hall, DJ Cook, RA Neiser, TJ Roemer, DA Hirschfeld, The effect of a simple annealing heat treatment on the mechanical properties of cold-sprayed aluminum, J. Therm. Spray Technol., 15 (2006), 233-238.

[55] S Bagherifard, J Kondas, S Monti, J Cizek, F Perego, O Kovarik, F Lukac, F Gaertner, Mario Guagliano, Tailoring cold spray additive manufacturing of steel $316 \mathrm{~L}$ for static and cyclic load-bearing applications, Materials \& Design, 203 (2021), 109575.

[56] N Hutasoit, RA Rahman Rashid, S Palanisamy, A Duguid, Effect of build orientation and post-build heat treatment on the mechanical properties of cold spray additively manufactured copper parts, Int. J. Adv. Manuf. Technol., 110 (2020), 2341-2357. 
[57] XT Luo, YK Wei, Y Wang, CJ Li, Microstructure and mechanical property of Ti and Ti6Al4V prepared by an in-situ shot peening assisted cold spraying, Mater. Des., 85 (2015), 527-533.

[58] XL Xie, CY Chen, YC Xie, ZM Ren, E Aubry, G Ji, HL Liao, A novel approach for fabricating Ni-coated FeSiAl soft magnetic composite via cold spraying, J. Alloys Compd., 749 (2018), 523-533.

[59] K Yang, WY Li, XW Yang, YX Xu, Achilles Vairis, Effect of heat treatment on the inherent anisotropy of cold sprayed copper deposits, Surf. Coat. Technol., 350 (2018), 519-530.

[60] N Phambu, Characterization of aluminum hydroxide thin film on metallic aluminum powder, Mater. Lett., 57 (2003), 2907-2913.

[61] XP Li, KM O'donnell, Tim B Sercombe, Selective laser melting of Al-12Si alloy: Enhanced densification via powder drying, Addit. Manuf., 10 (2016), 10-14.

[62] B Yu, J Tam, W Li, HJ Cho, J-G Legoux, D Poirier, JD Giallonardo, U Erb, Microstructural and bulk properties evolution of cold-sprayed copper coatings after low temperature annealing, Materialia, 7 (2019), 100356.

[63] S Hegde, K Narayan Prabhu, Modification of eutectic silicon in Al-Si alloys, J. Mater. Sci., 43 (2008), 3009-3027.

[64] XP Li, XJ Wang, Martine Saunders, Alexandra Suvorova, LC Zhang, YJ Liu, MH Fang, ZH Huang, Timothy B Sercombe, A selective laser melting and solution heat treatment refined Al-12Si alloy with a controllable ultrafine eutectic microstructure and $25 \%$ tensile ductility, Acta Mater., 95 (2015), 74-82.

[65] WY Li, CL Yang, HL Liao, Effect of vacuum heat treatment on microstructure and microhardness of cold-sprayed TiN particle-reinforced Al alloy-based composites, Mater. Des., 32 (2011), 388-394.

[66] CJ Huang, WY Li, Strengthening mechanism and metal/ceramic bonding interface of cold sprayed TiNp/A15356 deposits, Surf. Eng., 32 (2016), 663-669.

[67] G Liu, GJ Zhang, F Jiang, XD Ding, YJ Sun, J Sun, E Ma, Nanostructured high-strength molybdenum alloys with unprecedented tensile ductility, Nature materials, 12 (2013), 344-350. [68] H Li, XM Wang, LH Chai, HJ Wang, ZY Chen, ZL Xiang, TN Jin, Microstructure and mechanical properties of an in-situ TiB2/Al-Zn-Mg-Cu-Zr composite fabricated by Melt-SHS process, Mater. Sci. Eng., A, 720 (2018), 60-68.

[69] XP Li, G Ji, Z Chen, A Addad, Y Wu, HW Wang, J Vleugels, JV Humbeeck, JP Kruth, Selective laser melting of nano-TiB2 decorated AlSi10Mg alloy with high fracture strength and ductility, Acta Mater., 129 (2017), 183-193.

[70] Y Ma, A Addad, G Ji, MX Zhang, W Lefebvre, Z Chen, V Ji, Atomic-scale investigation of the interface precipitation in a TiB2 nanoparticles reinforced $\mathrm{Al}-\mathrm{Zn}-\mathrm{Mg}-\mathrm{Cu}$ matrix composite, Acta Mater., 185 (2020), 287-299. 
Conflict of Interest

\section{Conflict of interest}

The authors declared that they have no conflicts of interest to this work. 
Credit author statement

X. Xie: Methodology, Writing - original draft. C. Chen: Methodology, Investigation.

Z. Chen: Methodology, Conceptualization; A. Addad: Methodology, Investigation; Y. Xie: Methodology, Investigation; H. Wu: Methodology; C. Verdy: Methodology; Z.

Ren: Review, Conceptualization; G. Ji: Supervision, Writing, Review \& Editing. H. Liao: Conceptualization, Supervision, Project administration. 